\title{
New information on Titanichthys (Placodermi, Arthrodira) from the Cleveland Shale (Upper Devonian) of Ohio, USA
}

\author{
James Boyle $^{1}$ and Michael J. Ryan ${ }^{2}$ \\ ${ }^{1}$ Program in Evolution, Ecology, and Behavior, State University of New York at Buffalo, Buffalo, New York 14260, USA 〈jamesboy@buffalo.edu〉 \\ ${ }^{2}$ Department of Vertebrate Paleontology, Cleveland Museum of Natural History, Cleveland, Ohio 44106, USA〈mryan@cmnh.org〉
}

\begin{abstract}
The placoderm Titanichthys from the Late Devonian (Famennian) is based on incomplete and fragmentary specimens that have hindered understanding of its overall anatomy and phylogenetic relationships. A new, nearly complete, articulated specimen from the Upper Devonian Cleveland Shale provides new information about the previously undescribed rostral, postmarginal, postsuborbital, submarginal, posterior superognathal plates, and the nasal capsule. A revised diagnosis is provided for the genus. Three new diagnostic characters are identified, including a transversely elliptical rostral plate that does not contact adjacent plates, a reduced posterior superognathal, and a median dorsal plate that inserts into the posterior dorsal lateral plate. The first comprehensive phylogenetic analysis of Titanichthys indicates that the genus is a basal aspinothoracid arthrodire closely related to the enigmatic taxa Bungartius and Tafilalichthys.
\end{abstract}

\section{Introduction}

A speciose assemblage of sharks and arthrodires have been recovered from the Cleveland Shale (Famennian; a member of the Ohio Shale Formation) of Ohio beginning in the late nineteenth century (Carr, 1995). After Dunkleosteus (Dinichthys) terrelli Newberry, 1873, material identified as Titanichthys is the most common arthrodire collected from the shale. The taxon is one of the oldest known placoderms, established by Newberry in 1885. Originally placed in the family Dinichthyidae (Newberry, 1885), it was moved to its own family, Titanichthyidae, by Dean (1901). Five species of Titanichthys are currently recognized from North America (Titanichthys agassizi Newberry, 1885, Titanichthys clarki Newberry, 1887, Titanichthys attenuatus Claypole, 1893, Titanichthys hussakofi Claypole, 1894, and Titanichthys rectus Wright in Claypole, 1893), with the latter three only being known from fragmentary remains. Two additional species-Titanichthys termieri Lehman, 1956 and Titanichthys kozlowskii Kulczycki, 1957-are known from Morocco and Poland, respectively.

Although large, thin cranial plates recovered from the Cleveland Shale are often attributed to the genus Titanichthys, the genus is currently poorly diagnosed and is in need of revision (Carr, 1995). A recently collected, almost complete, articulated specimen (CMNH 50319) of Titanichthys, as well as CMNH 8981, an isolated median dorsal plate, and CMNH 5068, two sclerotic plates associated with a Titanichthys inferognathal, provide important new information of the previously undescribed rostral, postmarginal, postsuborbital, submarginal, posterior superognathal plates, and the nasal capsule of this taxon. This new data also allows Titanichthys to be rediagnosed and its phylogenetic relationships to other placoderms to be analyzed. Revisions of the named species are beyond the scope of this paper.

\section{Materials and methods}

A new specimen of Titanichthys, CMNH 50319, was excavated in 2007 from the banks of the Rocky River west of Cleveland, Ohio. The exact locality data is on file with the Cleveland Museum of Natural History to preserve the integrity of the site. CMNH 50319 is a mostly complete and articulated head shield and dorsal trunk shield held together by pyritization of the plates. CMNH 8981 and CMNH 5068 are isolated plates of Titanichthys recovered during the construction of route I-71 in the Cleveland area (1965 to 1966) and the exact locality is unknown. All the specimens came from the Cleveland Shale Member (Upper Devonian, Famennian) of the Ohio Shale Formation. The Cleveland Shale is interpreted as a relatively shallow foreland basin (Ettensohn, 1987) and is placed in the late expansa- early praesulcata conodont zones (Zagger, 1995).

Repositories and institutional abbreviations.-Figures and other specimens examined or compared in this study are deposited in the following institutions: American Museum of Natural History (AMNH), New York City, N.Y., USA; Cleveland Museum of Natural History (CMNH), Ohio, USA; Western Australian Museum (WAM), Western Australia, Australia.

Phylogenetic analysis.-The phylogenetic position of Titanichthys within the arthrodires has never been rigorously tested. In his review of placoderms, Denison (1978) listed Titanichthys as a pachyosteomorph of uncertain relations, and it has been treated as such up to the present time.

A parsimony analysis of Titanichthys cf. T. clarki (CMNH 50319) and 59 other arthrodires using the 121 characters of Zhu et al. (2015) was performed with PAUP 4.0b10 beta (Swofford, 2002); however, because some taxa were excluded (see below), 
only 118 characters were parsimony informative. Characters 1-85 were derived from Carr (1991), characters 86-98 were derived from Carr and Hlavin (2010), and characters 99-121 were taken from Zhu et al. (2015). Seven taxa scored by Zhu et al. (2015) were not included in our analysis because they were outside the clade of interest in this study and are poorly known. Enseosteus and Walterosteus were scored at the genus level by Rücklin et al. (2015), and this taxonomic level is retained here. Three pairs of congeneric species (Camuropiscis Dennis and Miles, 1979, Incisoscutum Dennis and Miles, 1981, and Torosteus Gardiner and Miles, 1990) were combined to give a genus-level coding, with conflicting characters recoded as polymorphisms to avoid double-counting of character transformations shared by congeneric species pairs (Trinajstic and Dennis-Bryan, 2009; Zhu et al., 2015). Trinajstic and DennisBryan (2009) examined the effects on tree topology of polymorphisms within coccosteomorphs using the Carr (1991) and the Carr and Hlavin (2010) matrices, plus additional taxa. Their study concluded that the best resolution was achieved when all polymorphic characters were included, rather than deleting them or using the modal states. This study follows the convention of coding all polymorphic characters.

The three species of Dunkleosteus were kept separate because two of the species (Dunkleosteus amblyodoratus and Dunkleosteus raveri Carr and Hlavin, 2010) are very poorly known, and their assignment to the genus remains uncertain (Zhu et al., 2015). The two species of Eastmanosteus were also kept separate because they have previously been reported (Carr and Hlavin, 2010; Zhu and Zhu, 2013; Zhu et al., 2015) to not be sister taxa, thus the genus may be paraphyletic.

For completeness, all taxa previously scored in analyses using the character set established by Carr (1991) are included in the character matrix (Supplemental Data) at the lowest taxonomic level available. Only the type species, Ti. agassizi, of Titanichthys was added to the analysis because the other species are either too poorly known (i.e., Ti. attenuatus, Ti. hussakofi, Ti. kowlowskii, Ti. rectus, and Ti. termieri) or the most recent descriptions are composited material of questionable affinity (i.e., Ti. clarki; Dean, 1909). Bungartius perissus Dunkle, 1947 and Tafilalichthys lavocati Lehman, 1956 were added to the phylogenetic matrix because they show some similarities to Titanichthys, are known from nearly complete material, and represent an under-represented portion of the eubrachythoracid tree. Kujdanowaspis podolica Stensiö, 1942 was designated as the outgroup taxon following Zhu et al. (2015).

Character changes and discrepancies.-Recent phylogenetic analyses of placoderm fish (Trinajstic and DennisBryan, 2009; Carr and Hlavin, 2010; Zhu and Zhu, 2013) have differed in their character codings. We reexamined published descriptions and illustrations to resolve the conflicting codings and list the character state changes we made in comparison to the matrix of Zhu and Zhu (2013) in the online Supplemental Data sets.

\section{Systematic paleontology}

Anatomical abbreviations. $-\mathrm{a} . \mathrm{Au}=$ depression for autopalatine; $\mathrm{ADL}=$ anterior dorsal lateral plate; $\mathrm{AL}=$ anterior lateral plate; $\mathrm{C}=$ central plate; cd.art $=$ region of articular condyle; cf.PL $=$ contact face for posterior lateral plates; cf.PN = contact face for postnasal plate; cf.SO = contact face for suborbital plate; ch.pro.pr $=$ channel for dorsal aspect of preorbital process of neurocranium; cr.po $=$ postocular crista; $c r . p r=$ carinal process; cr.pso $=$ posterior supraorbital crista; cr.sau $=$ subautopalatine crista; cr.so $=$ subocular crista; cr. seth $=$ supraethmoid crista; $\csc =$ central sensory canal groove; d.prp $=$ dermal preorbital process; d.ptp $=$ dermal postorbital process; f.lv = fossa on nuchal plate for levator muscles; f.p. = pineal fossa; $I G=$ inferognathal; ioc.ot $=$ otic branch of infraorbital canal groove; ioc.pt $=$ postorbital branch of infraorbital canal groove; ioc.sb = suborbital branch of infraorbital canal groove; $\mathrm{kd}=$ glenoid condyle; lam = laminae; lat.f = lateral fenestra of the head shield; $l c=$ main lateral line groove; $\mathrm{M}=$ marginal plate $\mathrm{MD}=$ median dorsal plate $\mathrm{mp}=$ middle pit-line groove; $\mathrm{m} . \mathrm{sept}=$ median septum; $\mathrm{n} . \mathrm{th}=$ nuchal thickening; $\mathrm{Nu}=$ nuchal plate; oa. $\mathrm{AL}=$ overlap area for anterior lateral plate; oa.MD = overlap area for median dorsal plate; occ $=$ occipital cross commissure; $\mathrm{P}=$ pineal plate; $\mathrm{pap}=$ pararticular process; $\mathrm{PDL}=$ posterior dorsal lateral plate; $\mathrm{PL}$ $=$ posterior lateral plate; $\mathrm{PM}=$ postmarginal plate; $\mathrm{pmc}=$ postmarginal sensory line groove; $\mathrm{PNu}=$ paranuchal plate; p.pr $=$ median posterior process of the nuchal plate; p.pro $=$ posterior process of the superognathal; $\mathrm{PrO}=$ preorbital plate; pr.sg $=$ subglenoid process; pr.SO $=$ suborbital process; $\mathrm{PSG}$ $=$ posterior superognathal; $\mathrm{PSO}=$ postsuborbital plate; psoc $=$ postsuborbital sensory canal groove; $\mathrm{PtO}=$ postorbital plate; pt.u = paired pits on visceral surface of nuchal plate; $\mathrm{qu}=$ quadrate $; \mathrm{R}=$ rostral plate; rec.PL $=$ collapsed recess for the posterior lateral plate; $\mathrm{SM}=$ submarginal plate; $\mathrm{SO}=$ suborbital plate; soc $=$ supraorbital sensory canal groove; sorc $=$ supraoral sensory canal groove; suo.v $=$ supraorbital vault .

Class Placodermi M'Coy, 1848

Order Arthrodira Woodward, 1891

Family Titanichthyidae Dean, 1901

Genus Titanichthys Newberry, 1885

Type species.-Titanichthys agassizi Newberry, 1885 from the Cleveland Shale, Ohio, USA.

Diagnosis.-Titanichthys is a large ( $>5 \mathrm{~m}$, adult size) aspinothoracid arthrodire with six autapomorphies: (1) head shield large and dorsoventrally compressed; (2) head shield with a length to width ratio of $0.5-0.54$ and thin plates $(1-10 \mathrm{~mm})$; (3) inferognathals are long and slender relative to the size of the head shield, acuspate, non-denticulated, and have anterior tips that projects ventrally to its longitudinal axis; (4) anterior border of the median dorsal plate deeply concave with two paired median processes extending from the lateral borders posterior to the nuchal gap; (5) supraoral sensory line groove and the suborbital branch of the infraorbital canal groove distinct, and form an open angle $\left(>90^{\circ}\right)$ on the suborbital plate; and (6) paired lateral fenestrae between the central, marginal, postorbital, and paranuchal plates of the head shield. 
Remarks.-The diagnosis for the genus Titanichthys was emended from that of Denison (1978, p. 100). The third autapomorphy of Titanichthys, lack of denticles or other occlusal surface on the inferognathal is undesirable from the perspective that an inferognathal not belonging to the genus might be misattributed if the oral margin has been weathered from exposure after death or from wear and advanced age in life. However, the presence of post-mortem weathering is usually detectable from other portions of the skeleton, if not from the inferognathal itself, and the loss of denticles from wear leads to a distinct shearing surface unlike that seen in Titanichthys (Dennis-Bryan, 1987; Carr, 1991). Further, the lack of denticles or occlusal surfaces on the inferognathal of Titanichthys is a derived loss within a phylogenetic context (see phylogenetic discussion section).

Titanichthys cf. T. clarki

Figures 1.1, 2, 3.1, 3.2, 4.1, 4.2, 5.1, 5.2, 6.1, $6.2,7.1,7.2,8.1,8.2,9.1,9.2,10,11,12.1$, $12.2,13,14,15.1,15.2,16,18.1,18.2$

Diagnosis.-The material referred to Titanichthys cf. T. clarki differs from all other described Titanichthys species in at least five features: (1) a pineal plate with a cardioid outline in external view; (2) a paranuchal plate which is expanded medially embaying the posterior margin of the central plate leading to an increased length of the central paranuchal plate contact; (3) proportionally small orbits; (4) the posterior margin of the median dorsal plate rounded; and (5) the insertion of the lateral margin of the median dorsal plate into the posterior dorsal lateral plate.

Descriptions.-The articulated specimen CMNH 50319 is interpreted as a subadult specimen of Titanichthys based on size, with affinities to Ti. clarki. An isolated median dorsal plate (CMNH 8981) preserves the carinal process lacking in $\mathrm{CMNH}$ 50319. Additionally, two sclerotic plates (CMNH 5068) referred to Titanichthys are also described. Some of the plates of CMNH 50319 were crushed during preservation, notably the right anterior portion of the head and thoracic shields, but otherwise there is little deformation of the specimens besides some compression artifacts.

CMNH 50319.- - Head shield: The head shield is large (maximum width $1116 \mathrm{~mm}$ ), slightly convex and with 13 plates preserved including paired $\mathrm{PrO}, \mathrm{PtO}, \mathrm{C}, \mathrm{M}, \mathrm{PM}$ and the median $\mathrm{R}, \mathrm{P}$, and $\mathrm{Nu}$ plates (Figs. 1, 2). The rostral (R) and postmarginal (PM) plates are described for the first time in the genus. A contact face on the preorbital plate provides evidence for the presence of the postnasal plates. The lack of contact between the rostral plate and the head shield suggests that these plates were loosely attached to the head shield in life and likely were transported away from the body before fossilization. The plates are thin $(1-10 \mathrm{~mm})$, with the exception of the nuchal and paranuchal plates where the nuchal and occipital thickenings, respectively, are well developed $(31 \mathrm{~mm})$. Connections for the neurocranium are greatly reduced compared to other euarthrodires (e.g., Eastmanosteus calliaspsis DennisBryan, 1987 [WAM 70.4.264], Westralichthys uwagedensis Long, 1987 [WAM 86.9.664], and D. terrelli [Lehman, 1956;
CMNH 5300]). CMNH 50319 shares with Gorgonichthys [Dinichthys] clarki Claypole, 1892 the presence of lateral fenestrae (lat.f, Fig. 3) formed by the margins of the central, preorbital, postorbital, and paranuchal plates (Dunkle and Bungart, 1940). The orbits are small compared to other arthrodires and enclosed by the suborbital, preorbital, and postorbital plates.

The plates are smooth and lack ornamentation. Most of the plates are preserved in articulation (held together by the partially pyritized matrix) through simple overlapping contacts. The exceptions to this are the rostral plate, which lacks any apparent contacts; the pineal plate's interdigitation with the central plates; and the paired central plates, which are interdigited along their midlines. Sensory canal grooves on the head shield plates follow the typical arthrodiran pattern, with the notable inclusion of the postsuborbital sensory canal groove that is uncommon in arthrodires from North America.

Rostral: The thin, ovoid rostral plate $(160 \mathrm{~mm} \times 79 \mathrm{~mm})$ (Figs. 1.4, 3, 4) of CMNH 50319 is the first evidence of this element from North America; unpublished material from Morocco includes several rostrals that can be referred to Titanichthys (Carr, personal communication, 2010). The plate was disarticulated and found resting on the dorsal surface of the pineal plate, and does not appear to have articulated with the rest of the head shield in life. The long axis of the rostral plate is inferred to be transverse from the wide anterior gap between the preorbital plates and the asymmetry of the perpendicular axis' borders. The longitudinally elliptical shape of the rostral plate differs from the T-shape of dunkleosteids, the triangular shape of coccosteomorphs, or the spade shape of apsinothoracids, and is here considered unique to Titanichthys within the pachyosteomorphs, with the possible exceptions of $\mathrm{Ta}$. lavocati (Lelièvre, 1991), Go. clarki (Dunkle and Bungart, 1940), Bruntonichthys multidens Dennis and Miles, 1980, and some selenosteids (e.g., Braunosteus schmidti Stensiö, 1959 and Enseosteus marocensis Rücklin, 2011).

Pineal: The pineal plate (Figs. 3, 4) of CMNH 50319 is cardioid shaped, most similar to Ti. termieri, but differing from the approximately rectangular and ovoid shapes of $T i$. clarki and Ti. agassizi, respectively. The transverse axial length (203 mm) is greater than the longitudinal length $(127 \mathrm{~mm})$. The plate has interdigited contacts with the central plates along its posterior border. The pineal does not contact the preorbital plates due to lateral gaps, contra previous descriptions of Titanichthys (e.g., Eastman, 1907; Dean, 1909). The pineal foramen is very small $(5 \mathrm{~mm})$. On the ventral surface of the plate the pineal fossa (f.p, Fig. 4.2) is completely bounded by a well-developed, laterally flared ridge. The ridge is the same cardioid shape as the pineal plate.

Nuchal: The nuchal plate (Figs. 3, 5) is the widest single plate of the head shield with a transverse length of approximately $600 \mathrm{~mm}$. The plate is laterally elongated with alae-like branches extending along the nuchal gap, which form an angle of approximately $150^{\circ}$. The anterior border of the nuchal plate is convex, a possible synapomorphy at the aspinothoracid level (Carr, 1991; but see Trinajstic and Dennis-Bryan, 2009 for discussion of variability in this trait), as is the concave emargination of the posterior border creating a large nuchal gap. The anterior edges of the alae are concave as in 


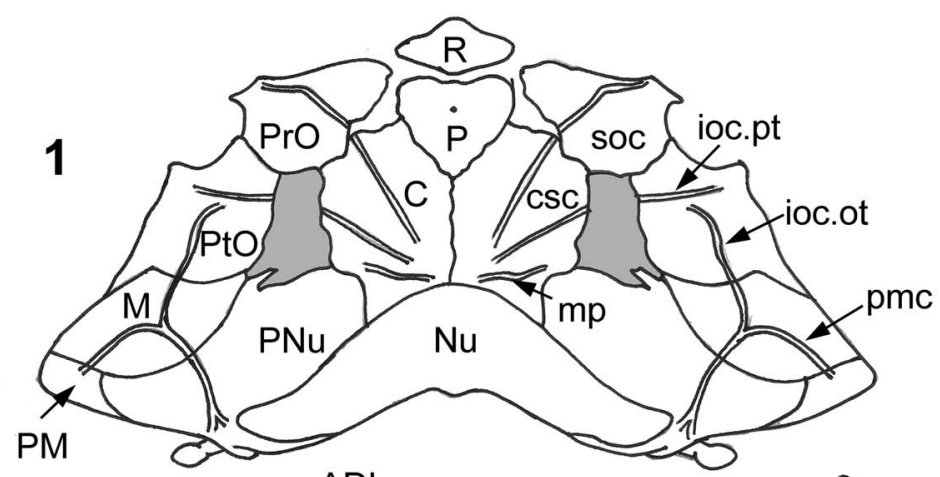

2
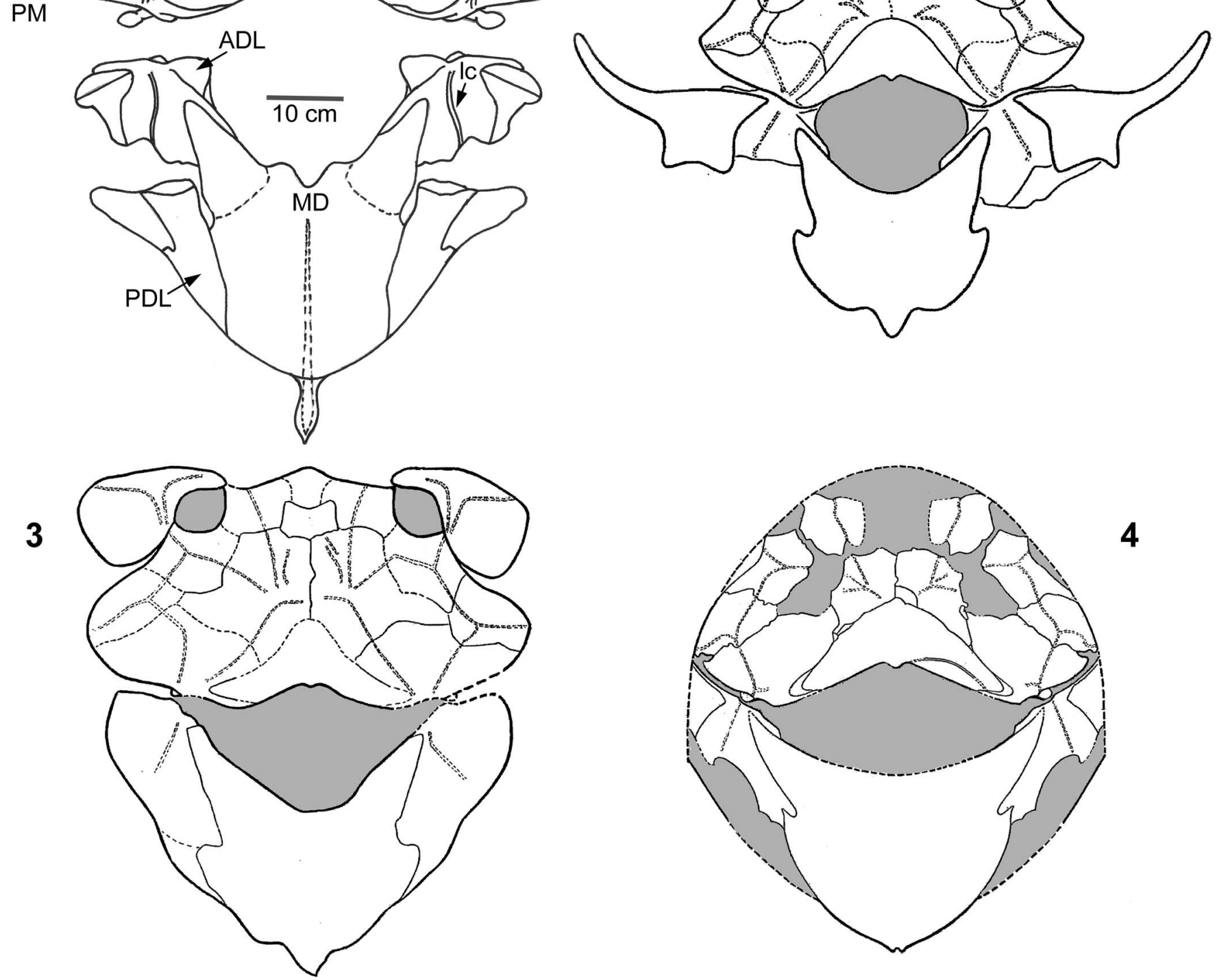

Figure 1. Reconstructions of Titanichthys in dorsal view. (1) Ti. cf. T. clarki (CMNH 50319), (2) Ti. agassizi (after Eastman, 1907); (3) Ti. clarki (after Dean, 1909); (4) Ti. termieri (after Lehman, 1956). Abbreviations in text.

Ti. agassizi and Ti. clarki, but unlike Ti. termieri where they are convex. There is a small, partially eroded, median posterior process on the nuchal plate (p.pr, Fig. 5.1).

On the posterior internal surface of the nuchal plate the median septum (m.sept, Fig. 5.1) is long ( $22 \mathrm{~mm}$ ), but very thin ( $25 \mathrm{~mm}$ at base), tapering posteriorly. The paired pits (pt.u, Fig. 5.1), separated by the median septum, are deep, narrow, and probably served as attachments for the neurocranium. These pits open posteriorly. The levator fossae (f.lv, Fig. 5.1), which are reduced compared to other arthrodires, are positioned dorsally to the paired pits on the interior surface. These fossae were sites of muscle attachment (Trinajstic et al., 2013) and their small size would seem to indicate a reduction in those muscles on $\mathrm{CMNH}$ 50319. The levator fossae and the paired pits on the internal surface of the nuchal of Ti. agassizi (Newberry, 1889, pl. 1) are wider than in CMNH 50319.

The median septum and paired pits are bounded anteriorly by a massive transverse nuchal thickening (n.th, Fig. 5.1) that 


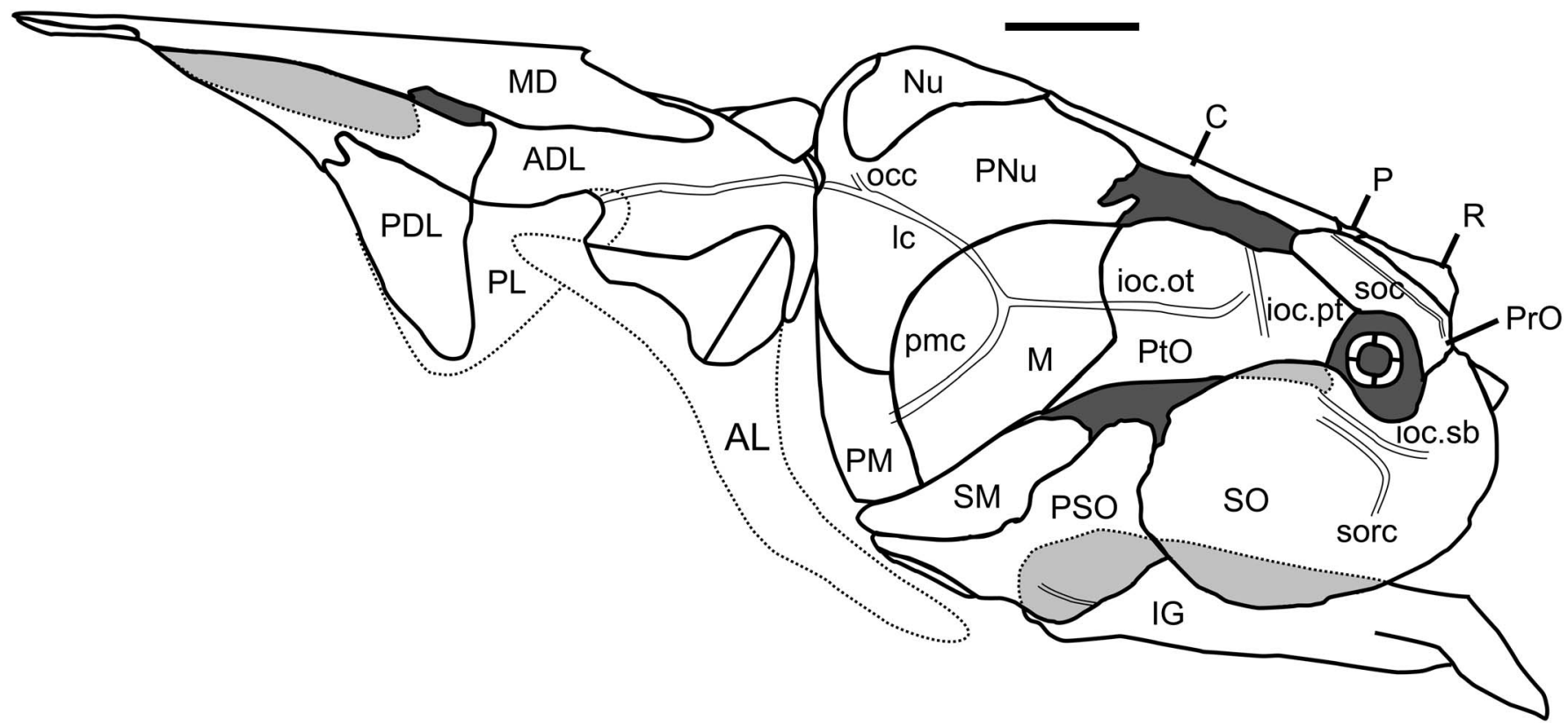

Figure 2. Reconstruction of Ti. cf. T. clarki (CMNH 50319) in lateral view. Scale bar $=10 \mathrm{~cm}$. The anterior lateral plate is a reconstructed composite of fragments from Ti. agassizi (Newberry, 1889) and Ti. termieri (Lehman, 1956). Lightly shaded regions indicate portions of plates that are overlapped externally. Dark shaded regions indicate empty space or fenestrae. Abbreviations in text.

extends the length of the entire plate and is continuous with the occipital thickening on the adjacent paranuchal plates. This nuchal thickening is approximately three times as thick $(31 \mathrm{~mm})$ as the thinnest part of the nuchal plate. The nuchal plate is overlapped externally by the central and paranuchal plates.

Preorbital: The preorbital plate (Figs. 3, 6) forms approximately one-third of the dorsal orbital border. The anterior portion of the preorbital plate projects medially toward the pineal and rostral plates, but does not contact either. The posterior medial portion of the preorbital plate slightly embays the central plate. The dermal preorbital process (d.prp, Fig. 6) is well developed, a trait common among Titanichthys (Newberry, 1889, pl. 1). The preorbital plates are overlapped by the central plates, and overlap the postorbital plates on the external surface. The supraorbital sensory line groove (soc, Fig. 6.2) crosses the preorbital plate ventrally where it forms a slight hook before tracing the margin of the preorbital dermal process, and becoming indistinct near the margin of the head shield. The ratio of the longitudinal length of central plate to the preorbital plate is approximately 0.55 when the maximum lengths of both plates are used. When the longitudinal length of the contact between the central plates is instead used, the central to preorbital length ratio is 0.92 . The ratio of maximum longitudinal length of the preorbital plate to the postorbital plate is approximately 0.84 .

The internal surface of the preorbital plate bears a slightly thickened supraorbital vault (suo.v, Fig. 6.1) that extends posteriorly onto the postorbital plate, and is bounded anteriorly by the channel for the dorsal aspect of the preorbital process of the neurocranium (ch.pro.pr, Fig. 6.1) and the dermal preorbital process. The dermal preorbital process is strongly ventrally curved and bears the contact surface for the suborbital plate (cf.SO, Fig. 6.1). Much of the anterolateral margin of the preorbital plate is comprised of a contact surface for the anterior process of the suborbital plate. A second, smaller contact surface on the internal surface of the preorbital plate, bounded posteriorly by the supraethmoid cristae (cr.seth, Fig. 6.1), is probably for the postnasal plate (cf. PN, Fig. 6.1) as seen in D. raveri (Carr and Hlavin, 2010); unfortunately, no postnasal plates are known for Titanichthys.

Postorbital: The postorbital plate (Figs. 3, 6) forms the posterodorsal margin of the orbit and makes up approximately two thirds of the total orbital margin of the head shield. It has an approximately rectangular shape with a posterolateral process that tapers to form part of the lateral margin of the head shield. The postorbital plate is overlapped by the marginal plate externally, but the contact between the central and the postorbital plate is incomplete due to the presence of a fenestrae.

The strongly ventrally curved dermal postorbital process (d.ptp, Fig. 6) is well-developed in contrast to the weakly developed (Heintzichthys [Dinichthys] gouldii Newberry, 1889 [Carr, 1991]) or absent (Gymnotrachelus hydei Dunkle and Bungart, 1939 [Carr, 1994], Stenosteus angustopectus Carr, 1996) postorbital processes of most aspinothoracid arthrodires. Three sensory canal grooves cross this plate; the central sensory canal groove (csc, Figs. 4.1, 6.2), the postorbital branch of the infraorbital sensory canal groove (ioc.pt, Fig. 6.2) and the otic branch of the infraorbital sensory canal groove (ioc.ot, Fig. 6.2). The central sensory canal groove is oriented anterodorsally from the medial margin of the postorbital plate. The postorbital branch of the infraorbital sensory canal groove is continuous with the central sensory canal groove and is oriented similarly, extending towards the postorbital plate's ventral margin. The otic branch of the infraorbital sensory canal groove is oriented approximately along the longitudinal axis and continues onto the marginal plate. The otic and postorbital branches of the infraorbital sensory canal groove are distinct and diverge from each other at an angle of approximately $60^{\circ}$. 


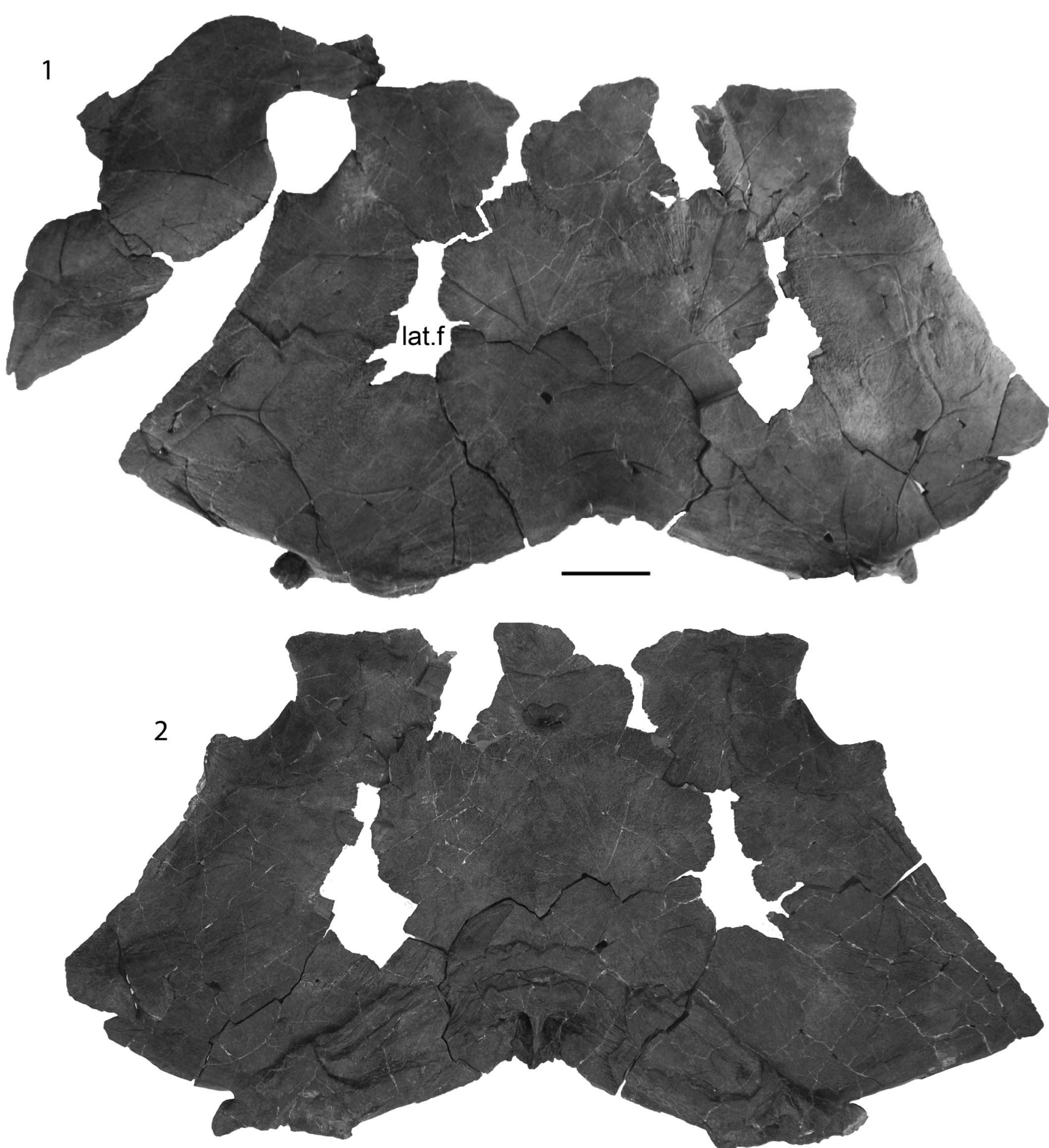

Figure 3. Titanichthys cf. T. clarki, CMNH 50319. (1) External and (2) internal views of the head shield. lat.f = lateral fenestra of the head shield. Scale bar $=10 \mathrm{~cm}$.

On the internal surface of the postorbital plate, the surpaorbital vault is continuous with the postorbital dermal process, becoming the posterior supraorbital crista (cr.pso, Fig. 6.1) along the posterolateral area of the plate. The posterior supraorbital crista is smaller than that in $H$. gouldii, and does not continue to the marginal plate. The entire supraorbital vault and its associated cristae are very poorly developed compared to other arthrodires. The posterior supraorbital crista on the left margin is studded by small $(5-7 \mathrm{~mm})$ lateral processes that project as posteriorly facing hooks. Their absence on the right side may indicate simple variation in plate structure or be a taphonomic artifact. CMNH 50319 lacks the inframarginal 


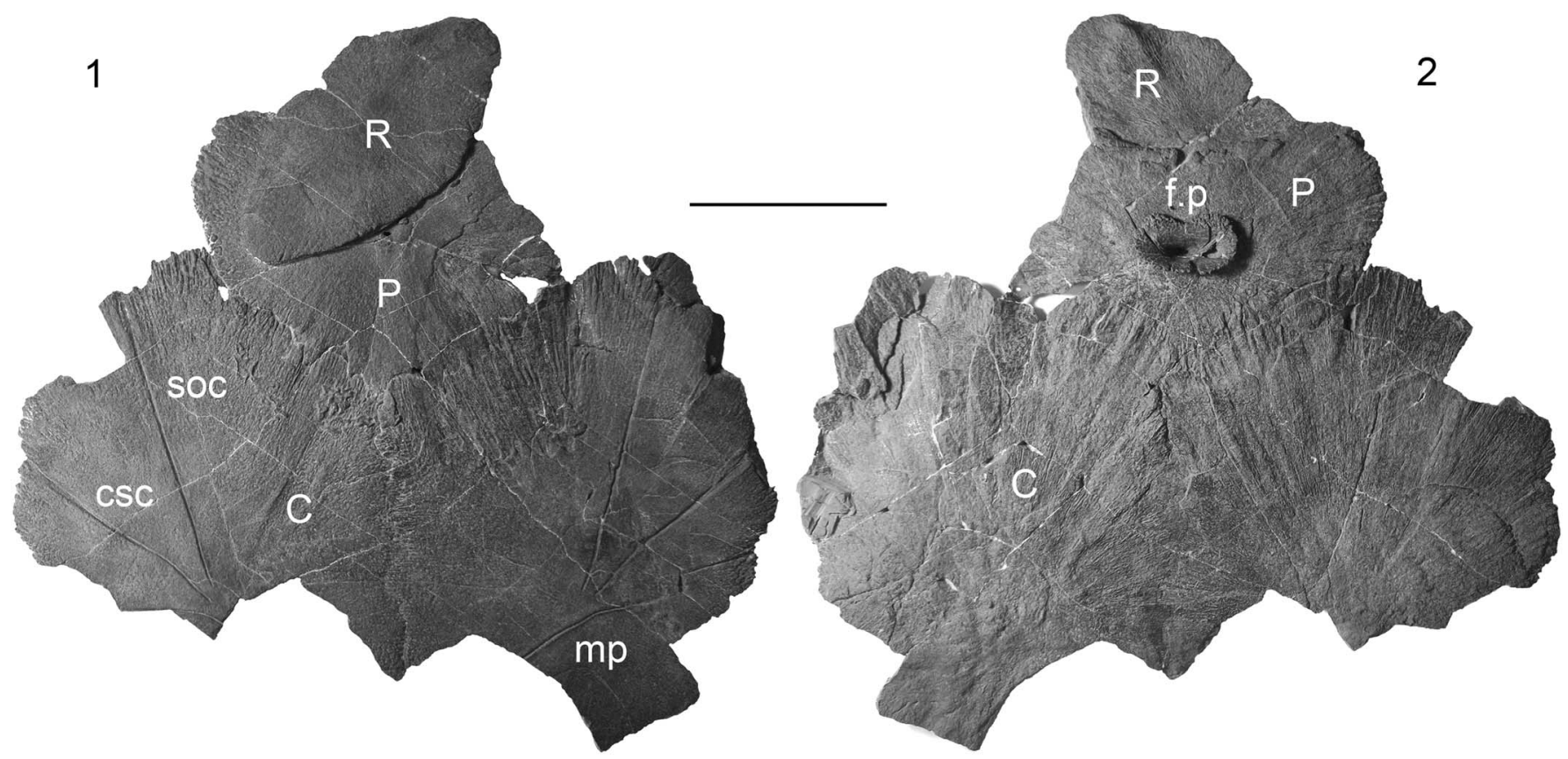

Figure 4. Titanichthys cf. T. clarki, CMNH 50319. (1) External and (2) internal views of rostral, pineal, and central plates. Abbreviations in text. Scale bar $=10 \mathrm{~cm}$.

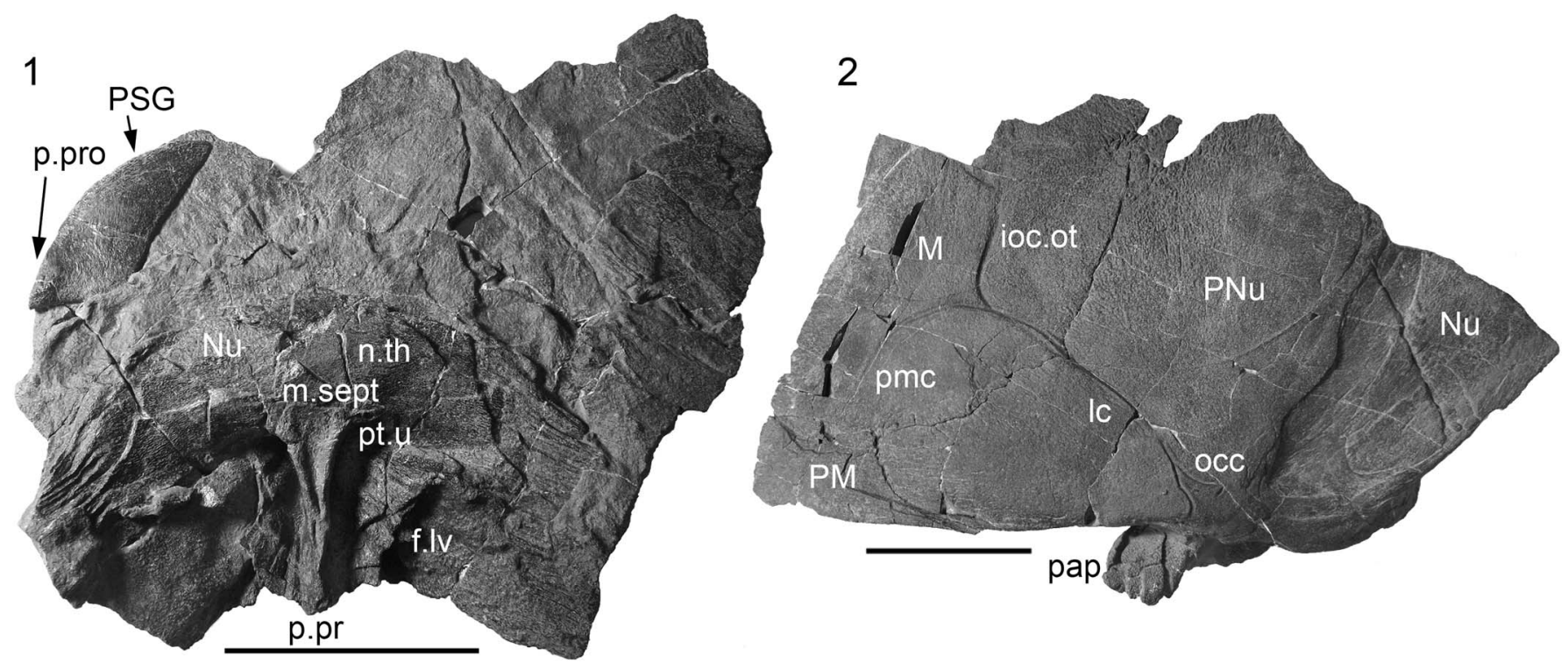

Figure 5. Titanichthys cf. T. clarki, CMNH 50319. (1) Internal view of the nuchal plate; (2) external view of paranuchal and marginal plates. Abbreviations in text. Scale bars $=10 \mathrm{~cm}$.

crista on the postorbital plates, a character state shared with Gy. hydei; the cristae are seen in other pachyosteomorph arthrodires (e.g., H. gouldii, D. terrelli, and S. angustopectus).

Central: The paired central plates (Figs. 3, 4) are preserved in CMNH 50319 with the lateral margin of the right plate partially crushed. The anterior margins are embayed where these plates contact the pineal plate giving the combined anterior margin of the central plates a U-shape. The central plates share a sinuous medial suture along approximately $55 \%$ of their maximum longitudinal length $(254 \mathrm{~mm})$, larger than the proportions seen on D. raveri (Carr and Hlavin, 2010) and Gy. hydei (Carr, 1994) (40\% and 33\%, respectively).
The boundaries with the preorbital and paranuchal plates may have been in contact, but fracturing of the plates in this extremely thin area $(<2 \mathrm{~mm})$ makes this assumption uncertain. The central plates lack any contact with the postorbital or marginal plates. A marginal-central-paranuchal or postorbital triple joint is lacking due to the intervening lateral fenestra. Externally, the posterior margins of the central plates overlap the nuchal plate.

There are three sensory canals present on the central plates. The supraorbital and central sensory line grooves continue onto the central plates from the preorbital and postorbital plates, respectively. Both the supraorbital and central sensory line grooves are aligned posteromedially, with the former having a 


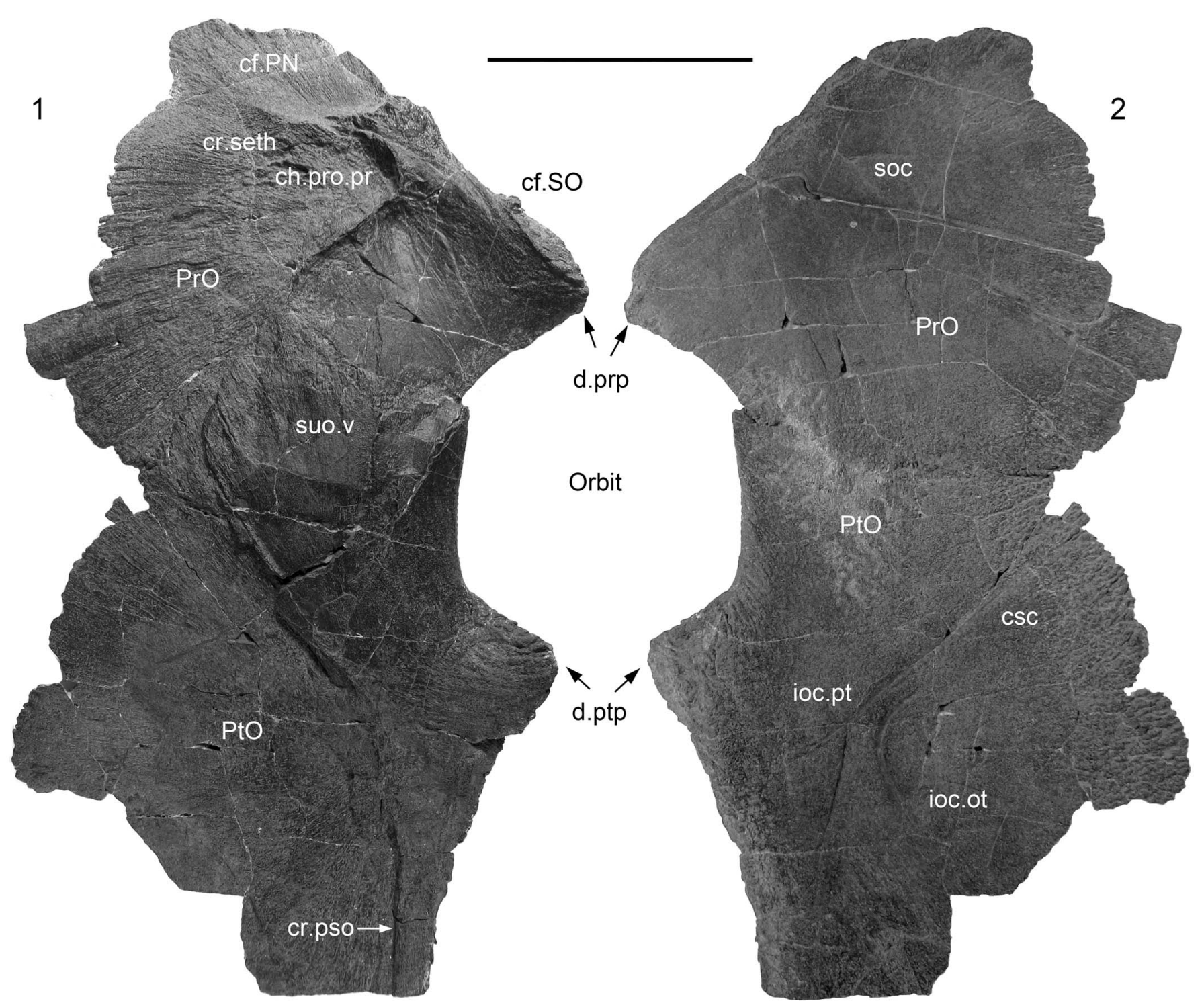

Figure 6. Titanichthys cf. T. clarki, CMNH 50319. Pre- and postorbital plates in (1) internal and (2) external views. Abbreviations in text. Scale $=10 \mathrm{~cm}$.

more acute angle to the longitudinal axis. These sensory lines approach each other in a V-shape close to the middle of the central plates, but do not intersect. There is a third groove (middle pit line groove, mp, Fig. 4.1) posterior to the supraorbital and central sensory line grooves, which forms a laterally oriented arc from a point anterior to the central-nuchal contact margin to the lateral fenestra.

A pre-endolympahtic thickening is absent on the ventral surface. The ossification center of the central plates can be determined from low radiating ridges, but they are not as well defined as those seen in D. terrelli.

Marginal: The marginal plate (Figs. 3, 5.2) is approximately elliptical in shape. The otic branch of the infraorbital line groove continues from the postorbital plate. It connects to the main lateral and postmarginal sensory line grooves (pmc, Fig. 5.2) near the center of the plate. The postmarginal canal groove continues posteroventrally onto the postmarginal plate, while the main lateral line groove (lc, Fig. 5.2) is aligned posterodorsally onto the paranuchal plate. The poorly developed infraorbital cristae are present, but do not continue onto the postmarginal plate. The marginal plate overlaps the central, paranuchal and the postmarginal plates.

Postmarginal: Only the left plate is preserved in CMNH 50319. The plate (Figs. 3, 5.2) is rectangular in shape and forms the posteroventral boundary of the head shield. A long $(108 \mathrm{~mm})$, but thin, posteromedial projection extends along the posterior margin of the paranuchal for approximately half the length between the posterolateral corner and the pararticular process. The postmarginal plate overlaps the paranuchal plate and is overlapped by the marginal plate externally. The postmarginal canal groove continues on the postmarginal plate from the marginal plate, diminishing in depth and width, and terminating $15 \mathrm{~mm}$ from the margin of the head shield.

Paranuchal: The paranuchal plate (Figs. 3, 5.2) of $\mathrm{CMNH}$ 50319 is irregularly shaped and expanded medially, similar to the pattern seen in Ti. termieri. It forms the posterior border of the lateral fenestra of the head shield. The paranuchal process extends posteriorly to the nuchal plate for a short distance where 

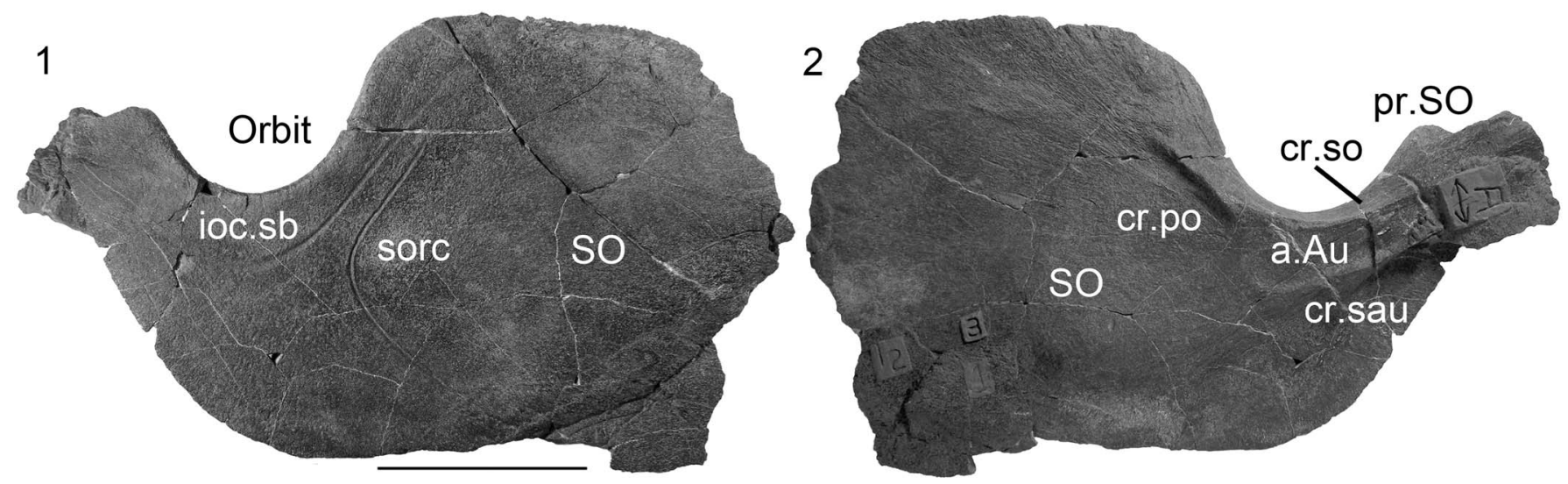

Figure 7. Titanichthys cf. T. clarki, CMNH 50319. Suborbital plate of CMNH 50319 in (1) external and (2) internal view. Abbreviations in text. Scale bar $=10 \mathrm{~cm}$.

it forms part of the nuchal gap border. The main lateral canal groove is oriented postero-medially ending just anterior to the well-developed pararticular process (pap, Fig. 5.2). The weakly developed occipital cross-commissure (occ, Fig. 5.2) branches medially from the main lateral canal groove a few centimeters anterior to the nuchal gap. Medial to the pararticular process, the lateral articular fossa is well developed on the posterior surface of the paranuchal plate. It is approximately horizontal in orientation, but slopes ventrally proceeding laterally. The nuchal thickening is continuous internally with the occipital thickening along the paranuchal plates posterior margins.

CMNH 50319.-Cheek Plates: The cheek plates are composed of three paired plates, suborbital, postsuborbital, and submarginal. Anteriorly the cheek plate is firmly attached to the head shield by an interlocking contact between the anterior of the suborbital plate and the preorbital process of the preorbital plates (Fig. 2). Posteriorly, the cheek plates appear to have been more loosely attached to the head shield based on depressions on the internal surface of the suborbital and submarginal plates that closely match the postorbital process of the postorbital plate and the lateral margin of the head shield. Only the left set of these plates were preserved. They are noticeably thicker $(10-27 \mathrm{~mm})$ than the plates of the head shield, with the exception of the nuchal plate which is thicker.

Suborbital: The suborbital plate (Figs. 3, 7) forms the ventral orbital border and is $292 \mathrm{~mm}$ in longitudinal length. The plate has a short, thick, anterior handle that curves dorsally to form the suborbital process (pr.SO, Fig. 7.2) that articulates with the dermal preorbital process. The suborbital process is not fully preserved, but the groove on the anterolateral margin of the preorbital indicates that it contacted the postnasal plate. The deep $(198 \mathrm{~mm})$ posterior portion, blade, of the suborbital plate curls strongly at the dorsal border. The plate tapers posteriorly and is overlapped by the postsuborbital.

The suborbital plate of Ti. termieri (Lehman, 1956) is similar, but smaller, than that of CMNH 50319, if the suborbital plate of Ti. termieri is complete. The distinct suborbital branches of the infraorbital canal groove (ioc.sb, Fig. 7.1) and supraoral sensory canal groove (sorc, Fig. 7.1) is shared with other species of Titanichthys, Gy. hydei, and Homosteus Asmuss, 1856 (Lehman, 1956). The two branches are parallel on the posteroventral margin of the orbit before diverging. The infraorbital branch extends to the blade, but terminates before reaching the suborbital plate's margin. The supraoral canal groove extends posteroventrally to nearly the margin of the suborbital plate. These two canals together form an open angle of approximately $100^{\circ}$. This angle is the same for Ti. clarki and Ti. termieri, and in contrast to Gy. hydei which has a more acute angle.

The subocular cristae (cr.so, Fig. 7.2) and subautopalatine cristae (cr.sau, Fig. 7.2) are preserved internally, and the former is almost continuous with the postocular cristae (cr.po, Fig. 7.2). A depression for the autopalatine (a.Au, Fig. 7.2) is well developed on the anterior process of the suborbital plate. There is a slight depression near the dorsal edge of the blade that is likely a contact for the postorbital process. There is no evidence for a contact face for the posterior superognathal on the linguiform process of the suborbital that exists in the Dunkleosteidae.

Postsuborbital: The postsuborbital plate (Figs. 3, 8) has an approximately triangular shape. The anterior edge has been broken along the overlap with the suborbital plate. The plate is overlapped posterodorsally by the submarginal plate. There is an anteroventral notch that creates a gap between the postsuborbital and suborbital plates, which has also been noted in at least one specimen of Gy. (CMNH 8054; Carr, 1994). The anterodorsal section of the postsuborbital plate has many short, sinuous, branching canals on the surface that may be remnants of vasculature. A postsuborbital sensory canal groove (psoc, Fig. 8.1) is present adjacent and parallel to the ventral border. This feature appears to be common among coccosteomorphs, but rare in pachyosteomorphs (e.g., Eastmanosteus calliaspis; Dennis-Bryan, 1987).

Internally, the quadrate (qu, Fig. 8.2) is perichondrally ossified with the articular condyle region (cd.art, Fig. 8.2) situated near the ventral border. As in most aspinothoracids, the postsuborbital plate extends posteriorly to a point, but this is greatly exaggerated in CMNH 50319 and several ridges are present on the plate's margin.

Submarginal: The ovoid submarginal plate (Figs. 3,8 ) is intermediate in shape between the stout, blocky plate of $S$. angustopectus and the elongated plate of $H$. gouldii. Its long axis parallels the lateral margin of the head shield to which the submarginal plate is loosely connected. The ossification center of the submarginal plate is marked on the internal surface by a medially placed knob near the posterior edge of the plate. There is a groove (gr, Fig. 8.2) for the hyomandibula on the medial dorsal border of the plate. 

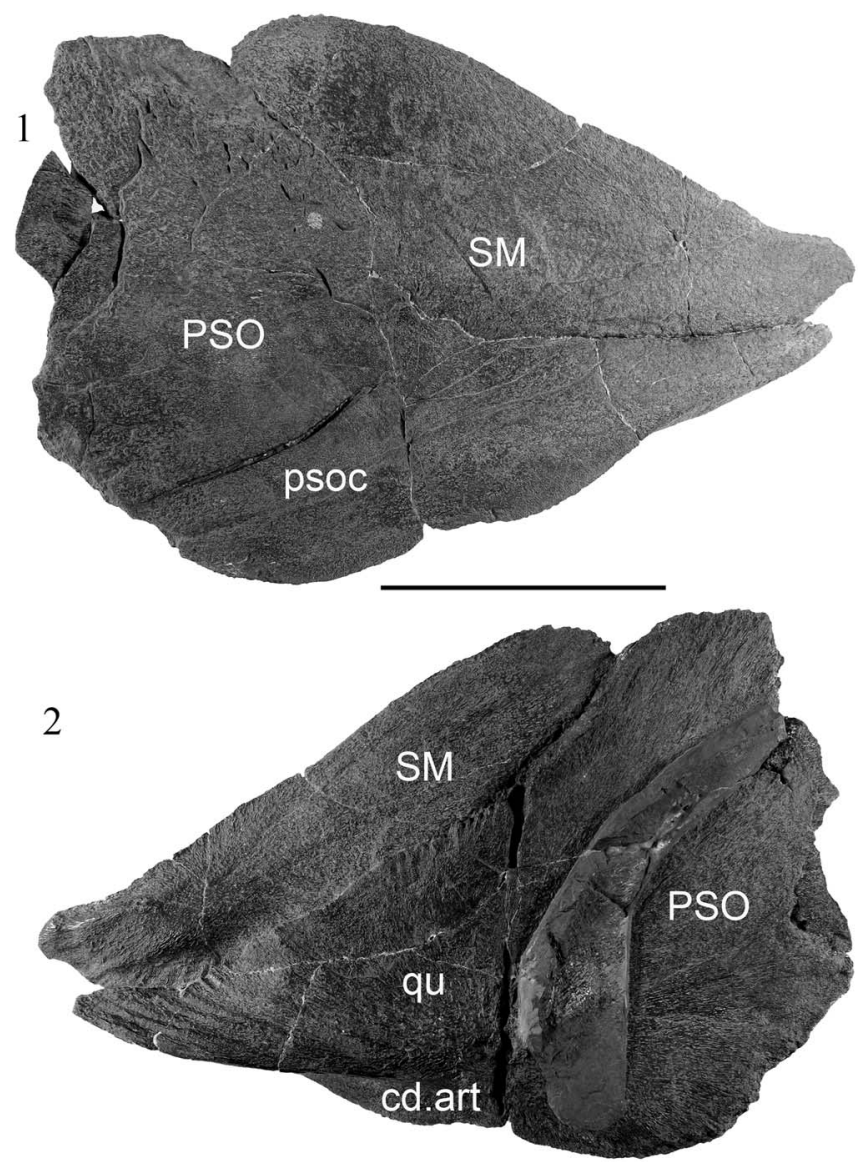

Figure 8. Titanichthys cf. T. clarki, CMNH 50319. Postsuborbital and submarginal plates of CMNH 50319 in (1) external and (2) internal view. Abbreviations in text. Scale bar $=5 \mathrm{~cm}$.

CMNH 50319. - Gnathal Plates: The gnathal plates in most arthrodires are composed of a set of three paired elements; inferognathals, anterior superognathals, and posterior superognathals. Only the left inferognathal and an isolated right posterior superognathal of CMNH 50319 are preserved.

Inferognathal: The left inferognathal of CMNH 50319 (Fig. 9) resembles that of the Ti. clarki holotype (AMNH 7315) in having a blade portion that is approximately two thirds the total length (total length approximately $610 \mathrm{~mm}$ ). There is a small notch (depth $16 \mathrm{~mm}$ ) on the posteroventral edge that is not observed on the type specimen (Newberry, 1889, pl. 2), although it is present on CMNH 6029 and is identical in shape, but longer (total length $730 \mathrm{~mm}$ ). The inferognathal is slightly convex longitudinally although its dorsal edge straightens anteriorly. The anterior portion of the inferognathal curves ventromedially $\left(39^{\circ}\right.$ vertically, $28^{\circ}$ medially relative to the long axis). A large ventral groove is present in the anterior half of the inferognathal for the meckelian cartilage and muscle attachments. There are no macroscopic wear marks on the inferognathal to indicate occlusion with the upper gnathal plates.

Superognathals: Superognathals are comprised of anterior and posterior plates. The first tentative Titanichthys superognathal discovered (an anterior) was assigned to Titanichthys by Hussakof (1930). Dunkle and Bungart (1946) later referred it to $G y$. and since then no superognathals have been found associated with Titanichthys. A small plate found on the underside of the right central plate in CMNH 50319 is here identified as the first posterior superognathal known from Titanichthys.

Posterior superognathal: Only the right posterior superognathal plate (Figs. 5.1, 10) of CMNH 50319 is preserved in medial view. It is sickle-shaped, a form shared with $H$. gouldii, B. perissus, Paramylostoma arcualis Dunkle and Bungart, 1945, and Richardosteus barwickorum from the Burrinjuck Limestone Formation of Australia, (Young et al., 2001; Long et al., 2014), but it is not elongate and is more strongly curved ventrally than the latter taxa. The plate has a near continuous thickness of approximately $0.5 \mathrm{~mm}$, and it lacks ornamentation (i.e., denticles or cusps). The posterior superognathal has a very small posterior process (p.pro, Fig. 10) that lies close to the dorsal margin. The dorsal border is convex while for all other Cleveland Shale arthrodires in which the posterior superognathal is known, the dorsal margin is concave. However, R. barwickorum shows this same orientation (Young et al., 2001, fig. 5).

CMNH 50319.-Dermal shoulder girdle: The elements historically recovered from the trunk shield have consistently been the median dorsal and anterior dorsal lateral plates which are the largest and most robust plates of the dermal shoulder girdle, respectively. Isolated plates of the dermal shoulder girdle have been assigned to Titanichthys (e.g., Heintz, 1931; Lehman, 1977, pl. 11), but, without any articulated material to compare them with these identifications should be taken as tentative. In Ti. termieri, articulated fragments of the anterior lateral plate are also known, but the posterior dorsal lateral plates, posterior lateral plates, and even the edges of the median dorsal plate in North American species, are unknown. CMNH 50319 has both pairs of posterior dorsal lateral plates and anterior dorsal lateral plates were preserved. Both sets are nearly complete and clear articulations for the posterior lateral and anterior lateral plates are visible. The median dorsal plate of CMNH 50319 only lacks the posterior margin, lost to erosion.

CMNH 50319 shows a unique pattern of thoracic plates interlocking (Figs. 1.1,2) that further differentiates the specimen from other arthrodires. It is not clear if this feature is characteristic of the Titanichthys genus as no other complete posterior dorsal lateral plates have been described. The posterior dorsal lateral plate has a pair of insertions, one for the posterior lateral plate and another for the median dorsal plate. Due to this unique pattern of overlap, only the basal part of the lateral median process of the median dorsal plate (posterior shaded portion of the median dorsal plate in Figure 1.1), a feature typical of Titanichthys, is visible. There are fenestrae present on each side of the thoracic shield between the overlap of the median dorsal plate onto the anterior dorsal lateral plate.

Median dorsal: The median dorsal plate (Figs. 3, 11) of CMNH 50319 is complete except for the posterior margin and the carinal process that have eroded away, although they are present on CMNH 8981. The plate lacks a median process on the anterior border in both specimens. The median dorsal plate is approximately as wide as it is long and has a two paired lateral processes that project anterolaterally. The anterior median processes are strongly developed and overlap the anterior dorsal lateral plates, while the lateral median processes are mostly covered as by their insertion into the posterior dorsal lateral. CMNH 50319 has a deep median embayment that extends 

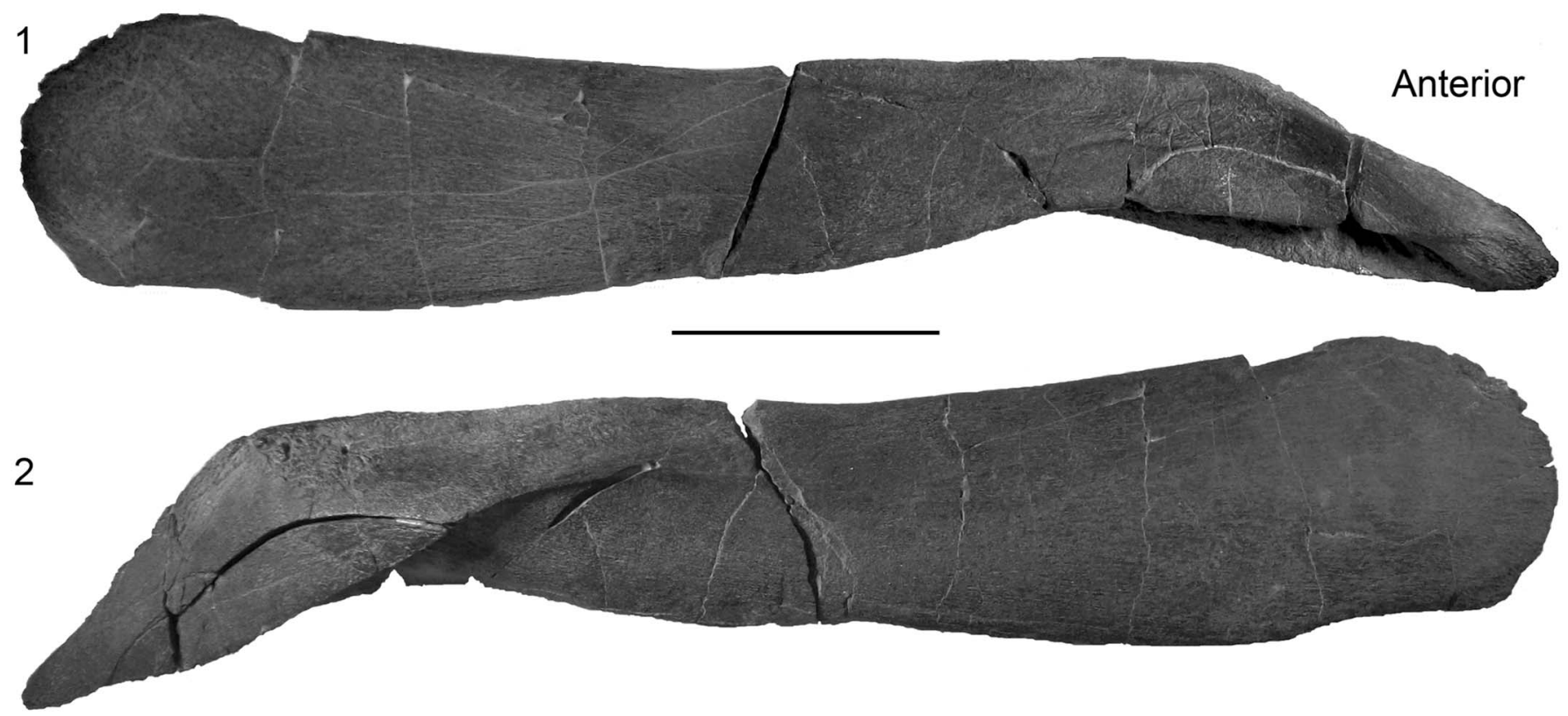

Figure 9. Titanichthys cf. T. clarki, CMNH 50319. Left inferognathal of CMNH 50319 in (1) medial and (2) lateral views. Scale bar $=10 \mathrm{~cm}$.

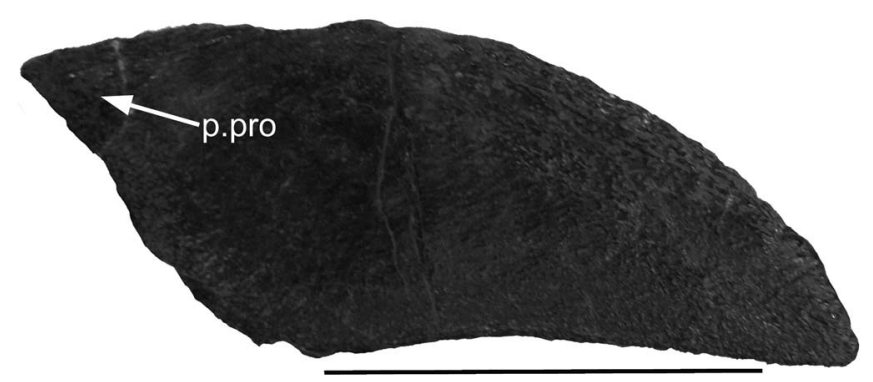

Figure 10. Titanichthys cf. T. clarki, CMNH 50319. Right posterior superognathal of CMNH 50319 in medial view. p.pro = posterior process of the superognathal. Scale bar $=5 \mathrm{~cm}$.

approximately $43 \%$ the total length of the element. This differs from the shallow concave margin that has previously been described for Ti. clarki and Ti. agassizi. A small keel is visible internally, although it is eroded posteriorly.

Anterior dorsal lateral: Both of the anterior dorsal lateral plates (Figs. 3, 12) are complete in CMNH 50319, with only the right side exhibiting slight signs of taphonomic alteration. The plate is robust and has a complex shape with three distinct lobes that are reminiscent of the morphology of this plate in Gy. hydei (Carr, 1994, fig. 11.4) and Go. clarki (Dunkle and Bungart, 1940, fig. 6). The medial-most lobe has the overlap area for the anterior median process of the median dorsal plate (oa.MD, Fig. 12.1) and extends laterally to form part of the nuchal gap margin. The medial-most lobe also projects beneath the median dorsal plate where it then thins at its broadest margin near the median embayment of the median dorsal plate. The middle lobe overlaps the posterior dorsal lateral plate. The lateral lobe of the anterior dorsal lateral plate is approximately rectangular in shape and has an overlap area for the anterior lateral plate. The external surface of the overlap area for the anterior lateral plate (oa.AL, Fig. 12.1) on the anterior dorsal lateral plate has two distinct regions of different thickness separated by a sharp demarcation. The thicker region covers approximately one third of the total contact surface and is anteriorly bounded by a posteroventrally oriented lamina (lam, Fig. 12.1).

The glenoid condyle (kd, Fig. 12) and the subglenoid process (pr.sg, Fig. 12) are well-developed with the latter being particularly robust, a feature noted for Ti. clarki (Lehman, 1956). Together, these form the articulation with the head shield. There appears to be a contact face internally for the posterior lateral plate (cf.PL, Fig. 12.2) between the medial and lateral lobes. The main lateral canal groove crosses the mid portion of the plate to its edge and may have continued onto the posterior lateral plate.

Posterior dorsal lateral: The posterior dorsal lateral plate (Figs. 3,13 ) has an elongate, triangular shape posteriorly, and bifurcates anteriorly. Unlike any other arthrodires that have a simple overlap with the median dorsal plate, CMNH 50319 has an insertion for the median dorsal plate on the posterior dorsal lateral plate. This insertion covers all but the base of the lateral median process of the median dorsal plate.

The lateral lobe of the anterior bifurcation of the posterior dorsal lateral plate contains an insertion, crushed during fossilization, for the posterior lateral plate (rec.PL, Fig. 13). The presence of an insertion for the posterior lateral plate is shared with Gy. hydei (Carr, 1994, fig. 11.3) and the superfamily Dunkleosteoidea (Carr and Hlavin, 2010). This insertion is located partially beneath the anterior dorsal lateral plate, but this may be a taphonomic artifact. The posterior dorsal lateral plate of Ti. termieri is incomplete, but also appears to have an insertion for the posterior lateral plate (Lehman, 1956, pl. 20.3).

Anterior lateral: The anterior lateral plate is not preserved in CMNH 50319, but the contact surface on the anterior dorsal lateral plate preserves an obtuse triangular outline for its dorsal aspect.

Posterior lateral: The posterior lateral plate is not preserved in CMNH 50319, but its outline can be implied from the shape of the overlapping region on the posterior dorsal lateral and anterior dorsal lateral plates. It had at least a small process that 


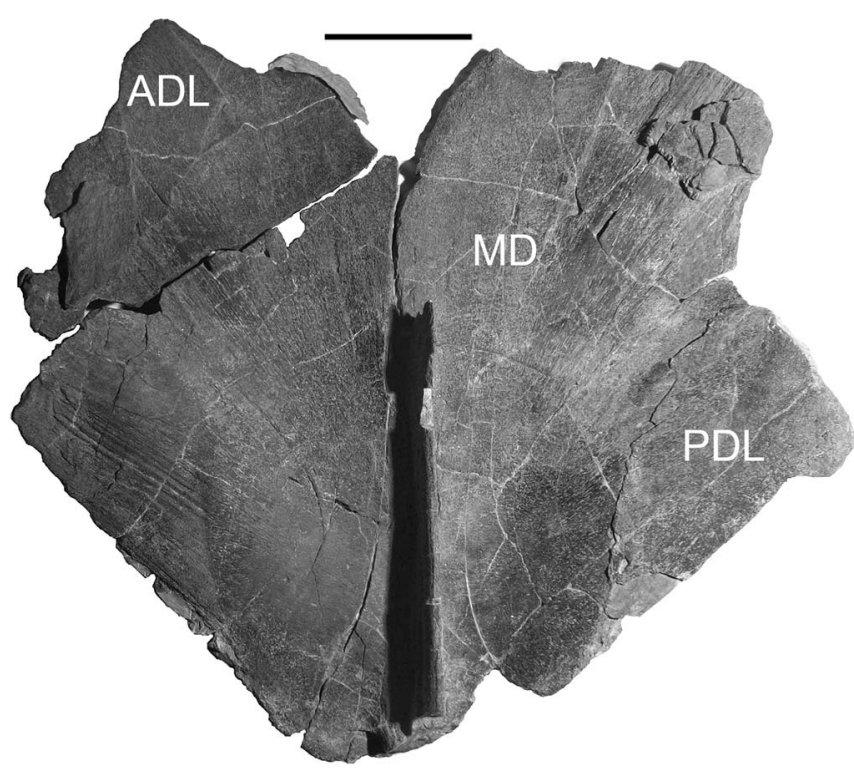

Figure 11. Titanichthys cf. T. clarki, CMNH 50319. Median dorsal plate in ventral view. Abbreviations in text. Scale bar $=10 \mathrm{~cm}$.

inserted into the posterior dorsal lateral plate, and, in order to articulate with the internal surface of the anterior dorsal lateral plate, it would have flared medially close to its base.

CMNH 50319.-Neurocranium: The neurocranium is rarely preserved in material from the Cleveland Shale with the exception of nasal capsules, which are partly ossified in some taxa. A single nasal capsule was found in association with CMNH 50319.

Nasal capsule: Only one of the nasal capsules (Fig. 14) is preserved in CMNH 50319. It was highly pyritized and compressed during burial. It is slightly wider than long at its base creating an ovoid outline. The element is well-ossified with a rough surface, a condition considered to be primitive among the arthrodires (Denison, 1978). The nasal capsule would have inserted into the small anterior depressions of the rostral plate.

CMNH 5068.--Sclerotic (scler): No sclerotic rings (Fig. 15) of Titanichthys have ever been formally described, although a sclerotic ring identified as belonging to Titanichthys (CMNH 7075) was used in a study of the ocular skeleton (Pilgrim and Franz-Odendaal, 2009); however, it was not associated with any definitive Titanichthys material. CMNH 5068, which is slightly larger than CMNH 50319 at $682.6 \mathrm{~mm}$ in length, has two complete sclerotic plates associated with a left inferognathal. The inferognathal of CMNH 5068 falls within the range of variation of $T i$. clarki and is assigned to this taxon on this basis.

Assuming that CMNH 5068 had four sclerotic plates in each eye arranged as in other arthrodires, the external diameter of the sclerotic ring would have been approximately $35 \mathrm{~mm}$, with an internal diameter of approximately $13 \mathrm{~mm}$. The orbit of Titanichthys cf. T. clarki is small for the length of its head shield (ratio of 0.21 for character 28) compared to other arthrodires, but the reconstructed dimension of the sclerotic ring would still not fill the entire orbit as it does in D. terrelli. The sclerotic plates show no ornamentation as seen in Gy. hydei or $S$. angustopectus (Carr, 1994, 1996). Internally, there is a ridge that parallels the outer border, with radiating growth rays originating from just behind this ridge.

CMNH 8981.-Median dorsal (MD). CMNH 8981 (Fig. 16) is a complete median dorsal plate that shows the same median embayment as seen on CMNH 50319. Based on the size of the plate, its gracile nature, and the presence of paired median processes, this plate is provisionally assigned to $T i$. cf. $T$. clarki. With a longitudinal length of $544 \mathrm{~mm}$ from the end of the carinal process (cr.pr) to the anterior embayment, the plate is $5 \%$ larger than CMNH 50319. The length of the embayment $(57 \mathrm{~mm})$ is approximately $14 \%$ of the total length of the plate. The posterior margin of the median dorsal plate of CMNH 8981 has a rounded edge with a long carinal process $(152 \mathrm{~mm})$. There is a narrow medial ridge on the ventral surface extending the length of the process. The base of the process has paired thin lateral projections and tapers posteriorly to a blunt tip. A shallow keel on the inferior surface is continuous with the carinal process posteriorly, but it does not reach the anterior embayment of the median dorsal plate.

Materials.-CMNH 50319, mostly complete and articulated head shield, left cheek plates and gnathal plates, and dorsal thoracic plates. $\mathrm{CMNH} 5068$, complete sclerotic ring and associated inferognathal. CMNH 8981, complete median dorsal plate.

Remarks.-In CMNH 50319 the pineal plate is cardioid in outline differing from the elliptical, rectangular, and subelliptical forms of Ti. agassizi (Newberry, 1889, pl. 1), Ti. clarki (Dean, 1909 pl. 40), and Ti. termieri (Lehman, 1956, fig. 12), respectively. The orbits of CMNH 501319 are slightly smaller (65-88\%), in proportion to the skull roof, than those of other well-known species. However, orbit size can change throughout ontogeny (Trinajstic and Hazelton, 2007) and the probable subadult status of this specimen makes this unique character questionable. The unique pattern of insertion of the median dorsal plate into the posterior dorsal lateral plate is admittedly questionable as the posterior dorsal lateral plate is only known from one other species, Ti. termieri.

Although CMNH 50319 has several characters not observed in other species, the generally poor preservation of the genus and the lack of recent anatomical descriptions make it difficult to discount intraspecific, or even individual, variation as the source of unique features. Until a complete review of all species of Titanicthys can be undertaken, CMNH 50319 is provisionally referred to $T i$. cf. $T$. clarki based on the following characteristics: (1) the inferognathal falls within the range of variation observed for Ti. clarki and is not strongly curved in the horizontal plane, (2) the ventral groove of the inferognathal is deep and bounded on both sides by lamina, and (3) the glenoid condyle and subglenoid process of the anterior dorsal lateral plate are robust and well developed. CMNH 5068 is also assigned to Titanichthys cf. T. clarki based on the shape of the inferognathal, while CMNH 8981 is assigned to Titanichthys $\mathrm{cf}$. T. clarki based on the form of the median anterior border of the median dorsal plate that is shared with CMNH 50319.

The difficulty of species assignment for CMNH 50319 is also complicated by its probable subadult status based on size, the lack of knowledge about the inferognathal of Ti. termieri 


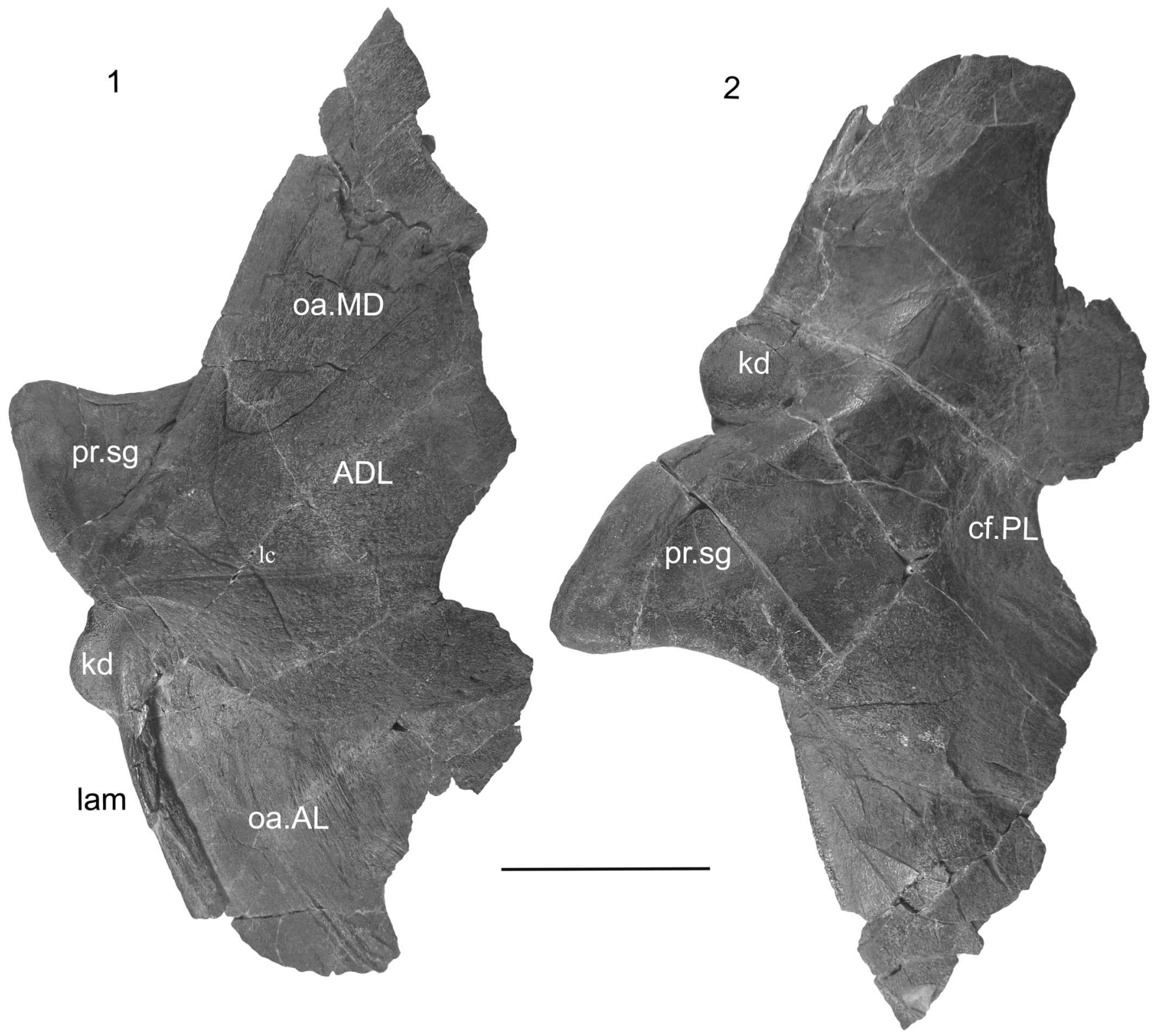

Figure 12. Titanichthys cf. T. clarki, CMNH 50319. Anterior dorsal lateral plate in (1) external and (2) internal views. Abbreviations in text. Scale $\mathrm{bar}=10 \mathrm{~cm}$.

(for comparative purposes), and that the most recent description and reconstructions of Ti. clarki (Dean, 1909) are based on a composite specimen.

\section{Discussion}

Phylogenetic discussion.-A strict consensus (Fig. 17; consensus tree length: 625 ; consistency index [CI]: 0.23 ; retention index [RI]: 0.59 ) of the 2,769 most parsimonious trees (tree lengths: 595) recovers Titanichthys cf. T. clarki as the sister taxon to Titanichthys agassizi in a basal monophyletic aspinothoracid clade with B. perissus and Ta. lavocati as successive outgroups.

As noted by Zhu and Zhu (2013), the tree topology of brachythoracid arthrodires is unstable and this is reflected by the low consistency index and high number of equally parsimonious trees recovered here. Much of this instability is likely due to the large proportion (38\%) of the dataset being coded as either unknown (?) or not applicable (-). Additional difficulties in resolving relationships are due to the higher number of polymorphisms coded compared to previous studies (but see Trinajstic and Dennis-Bryan, 2009, for an exception). The lack of resolution is also due, in part, to the low ratio of characters to taxa (2.01 characters/taxon) reducing the likelihood that most branches will be strongly supported (Bremer et al., 1999) and increasing the chance that the phylogeny will be misled by homoplasy. Despite all these potential shortcomings, some relationships seem to be robust and are discussed below.

Our analysis found support for most previously recognized large clades. The monophyletic coccosteomorphs (node A, Fig. 17) 


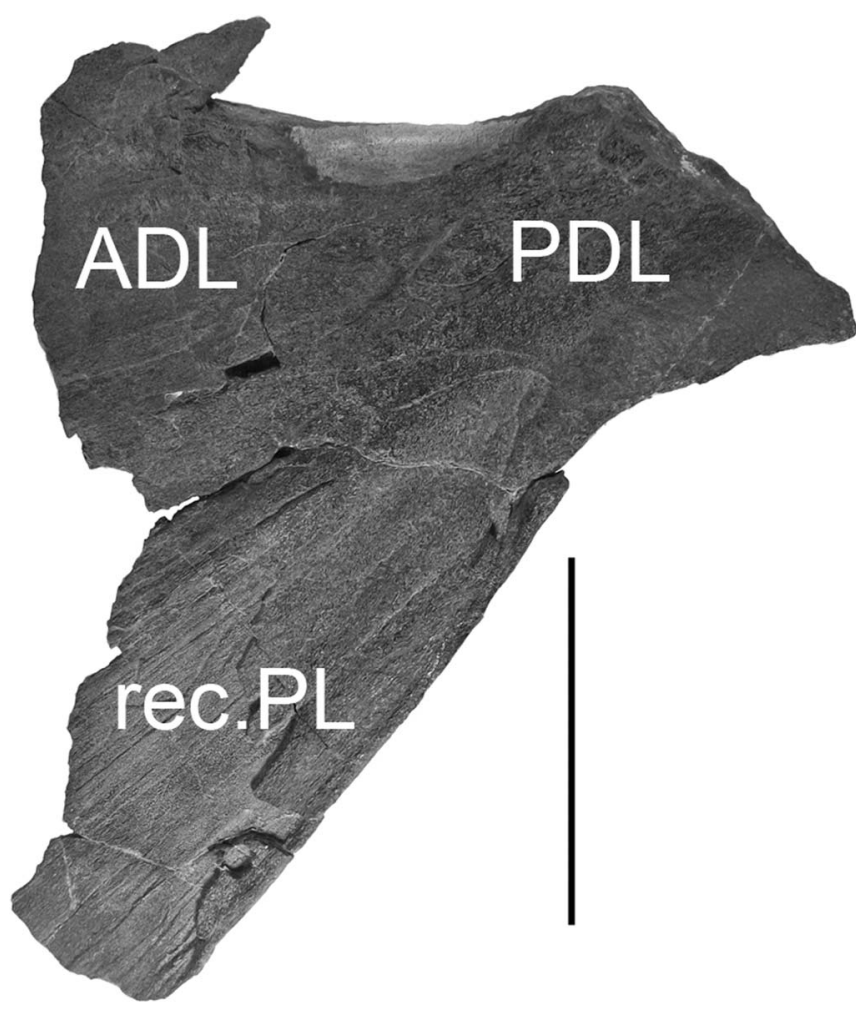

Figure 13. Titanichthys cf. T. clarki, CMNH 50319. Anterior portion of the posterior dorsal lateral plate in external view. Abbreviations in text. Scale bar $=10 \mathrm{~cm}$.

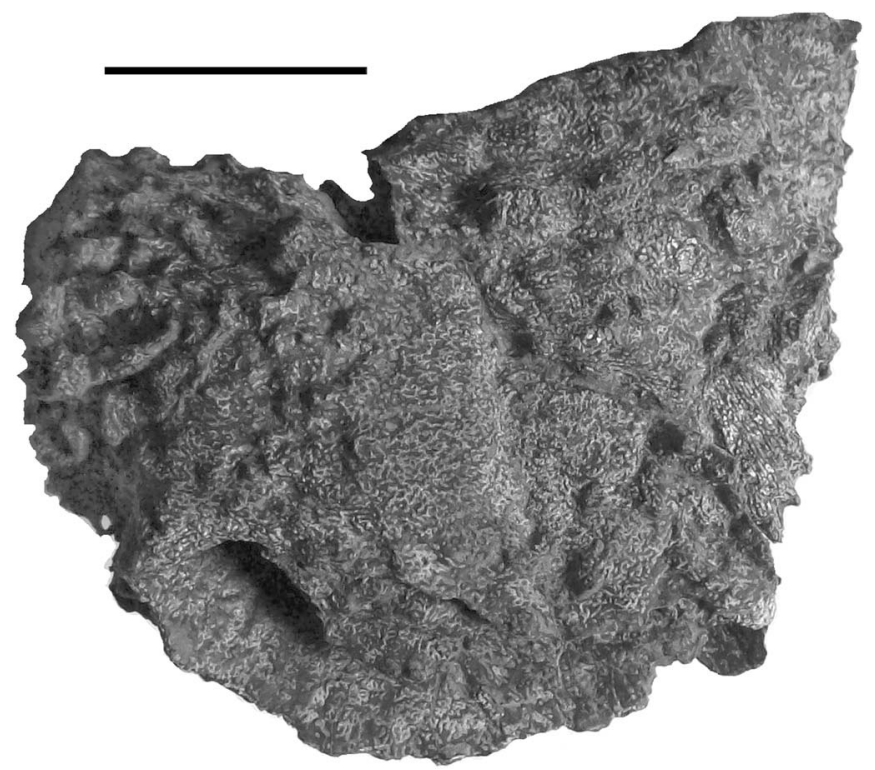

Figure 14. Titanichthys cf. T. clarki, CMNH 50319. Nasal capsule in dorsal view. Scale bar $=2 \mathrm{~cm}$.

are supported by a spinuous posterior border of the median dorsal plate (character 37, state 1), a pectoral dermal fenestrae (character 41 , state 0 ), and the presence of the ventral lamina on the posterior lateral plate (character 44, state 1). Coccosteomorphs are recovered as the sister-clade to the non-Dunkleosteoidea pachyosteomorphs, making the pachyosteomorphs paraphyletic in this analysis

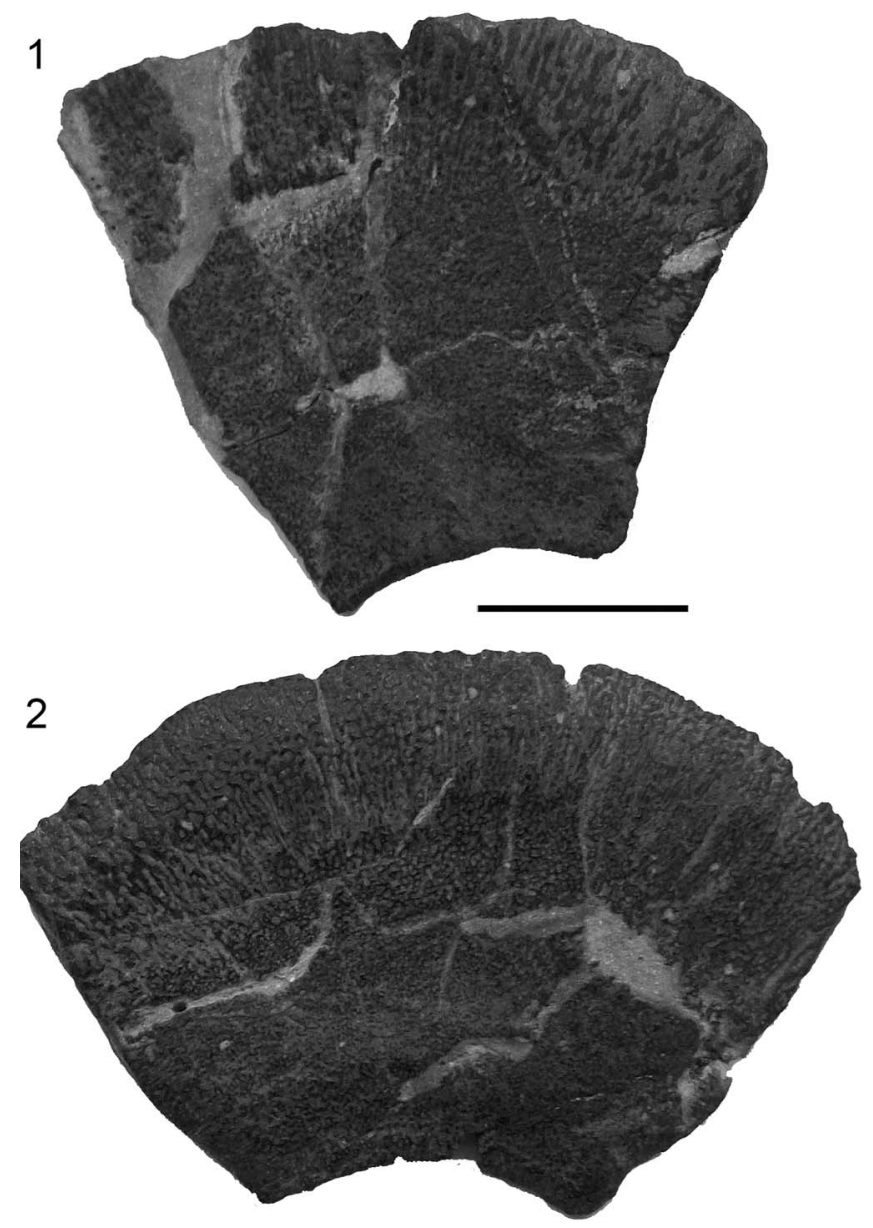

Figure 15. Titanichthys cf. T. clarki, CMNH 5068. Sclerotic plates of in (1) external and (2) internal views. Scale $b a r=2 \mathrm{~cm}$.

showing that even some high-level clade relationships remain unclear. Dunkleosteoidea are also found to be paraphyletic, with a polytomy of several taxa at the base of the eubrachythoracid clade. The other branch of the pachyosteomorphs contains the monophyletic Aspinothoracida (node B, Fig. 17), along with several basal taxa that retained spinal plates (i.e., Hadrosteus rapax Gross, 1932, Bullerichthys fascidens Dennis and Miles, 1980, and Kendrickichthys cavernosus Dennis and Miles, 1980). Aspinothoracida are united by the absence of an embayment of the central plate by the paranuchal plate (character 14, state 0 ), the absence of a contact between the marginal and central plates (character 23, state 0 ), and the eponymous synapomorphy of the group, the lack of a spinal plate (character 45, state 0 ). Aspinothoracida contains a basal clade comprising Titanichthyidae plus B. perissus and Ta. lavocati (node D, Fig. 17), and a more derived group containing H. gouldii, Go. clarki, and the Selenosteidae. A monophyletic Selenosteidae (node C, Fig. 17) is supported by a marginal plate that forms part of the orbit's border (character 25, state 1), a median dorsal plate with a non-spatulate posterior process (character 35, state 1), a broad submarginal plate (character 60 , state 0 ), the presence of an anterior dental field (character 64, state 1), the absence of an enclosed lateral face on the anterior superognathal plate (character 67, state 0), a closed angle between the postorbital and otic branches of the infraorbital sensory groove (character 75, state 2), and the presence of a stem-like prehypophysial region of the parasphenoid plate 


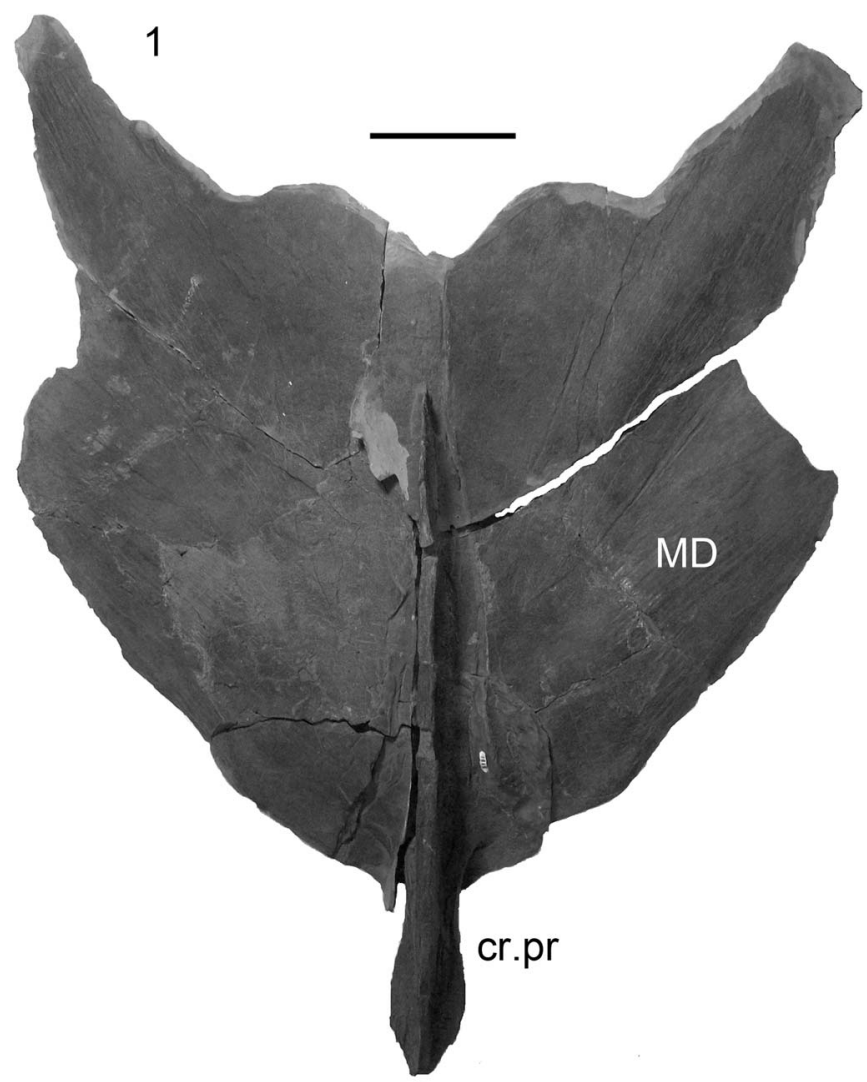

Figure 16. Titanichthys cf. T. clarki, CMNH 8981. Median dorsal plate in ventral view. Abbreviations in text. Scale bar $=10 \mathrm{~cm}$.

(character 112, state 1) contra recent phylogenetic analyses that recovered the group as paraphyletic (Carr and Hlavin, 2010; Rücklin, 2011; Zhu and Zhu, 2013; Rücklin et al., 2015, Zhu et al., 2015). The relationships within the Selenosteidae remain uncertain with little consensus among previous analyses (Lelièvre et al., 1987; Rücklin, 2011; Zhu et al., 2015), and this one. However, the taxa Gym. hydei and Ste. angustopectus do appear to be consistently basal within Selenosteidae.

The monophyletic group containing the two Titanichthys taxa, plus B. perissus, and Ta. lavocati are the outgroup to the clade of (Go. clarki + H. gouldii + Selenosteidae [node C]). These four taxa are united by three unambiguous characters including the position of the $\mathrm{C} / \mathrm{PNu} / \mathrm{M}$ or $\mathrm{PtO}$ triple point posterior to the $\mathrm{PNu} / \mathrm{C} / \mathrm{Nu}$ triple point (character 31 , state 0 ), the absence of an enclosed lateral face on the anterior superognathal (character 67, state 0), and a pineal plate with an external surface that is short and broad (character 101, state 0). However, the anterior superognathal of both Titanichthys taxa are unknown and, thus, the second synapomorphy remains equivocal. The first and third synapomorphies of this clade are both morphologies associated with the enigmatic family Mylostomatidae (Dean, 1901) with the posterior position of the $\mathrm{C} / \mathrm{PNu} / \mathrm{M}$ or $\mathrm{PtO}$ triple point due to the large size and elongation of the paranuchal plates. This clade is most often associated with large crushing surfaces, presumably for a durophagous lifestyle, but see Diplognathus for a possible exception (Dunkle and Bungart, 1943; Carr and Jackson, 2005). Tafilalichthys has been provisionally assigned to Mylostomatidae (Lehman, 1956;
Lelièvre, 1991) and, although B. perissus has been placed in its own family (Bungartidae; Denison, 1975), it shares the unusual character of having fused anterior superognathals with the type genus of Mylostomatidae, Mylostoma, suggesting a close affinity between the taxa (Dunkle, 1947). The original description of $B$. persissus also noted that it shared a number of features with Titanichthys. In particular, both genera have a ventro-mesially directed anterior tip and a relatively long blade portion of the inferognathal and a suborbital plate with a high short blade. The derived position of Titanichthys within a clade comprising likely members of the Mylostomatidae is interesting as it would suggest that a filter-feeder arose from a specialized durophagous lineage. However, the position and relations of Mylostomatidae remain uncertain as the phylogenetic position of its possible members (Mylostoma, Diplognathus, and Paramylostoma) have never been evaluated rigorously. Redescription of museum specimens and new material are needed to confirm whether Mylostomatidae is a true clade and if Titanichthys is nested within it.

The family Titanichthyidae (node E, Fig. 17), here represented by $T i$. agassizi and CMNH 50319, is united by four unambiguous characters including the position of the posterior edge of pineal plate posterior to the orbits (character 9, state 1), well-developed embayments of the central plates by the paranuchal plates (character 14, state 2), the position of the $\mathrm{PrO} /$ $\mathrm{PtO} / \mathrm{C}$ triple junction posterior to the orbit (character 33, state 0), and the presence of skull roof fenestrae (character 109, state 1). Characters 9 and 14 are both related to the reduction in orbit size of Titanichthys rather than a posterior shift of other features. CMNH 50319 shows three apomorphies in the phylogenetic analysis including a short contact between the central and nuchal plates (character 21, state 0 ), a reduction in the size of the orbits so that they are very small relative to skull size (character 28 , state 0 ), and a moderate extension of the skull roof anterior to the junction of the otic and postorbital branches of the infraorbital canal relative to the skull roof length posterior to that junction (character 93, state 1). It should be noted that all three of these apomorphies are ratios that are more likely to be variable between individuals than strict categorical characters (e.g., presence/absence) and possibly affected by ontogeny assuming CMNH 50319 is a subadult.

New and reinterpreted characters.-CMNH 50319 provides important new information about the genus, including descriptions of previously unknown plates: rostral, postmarginal, postsuborbital, submarginal, posterior superognathal, and nasal capsule. It also confirms the presence of paired lateral fenestrae on the head shield and the orientation of the inferognathal such that the distinctive groove is on the ventral surface. In addition, CMNH 50319 has three novel characteristic that may be diagnostic for the genus, dependant on confirmation in additional specimens, including: (1) a transversely elliptical rostral plate lacking contacts with the skull roof, (2) the presence of an insertion for the median dorsal plate on the posterior dorsal lateral plate, and (3) a reduced posterior superognathal (approximately 16\% the length of inferognathal) lacking denticles or an occlusal surface.

The lack of a well-defined contact between the rostral plate and any plates of the head shield in Titanichthys has led some authors to suggest that it had a soft snout (Dunkle and Bungart, 


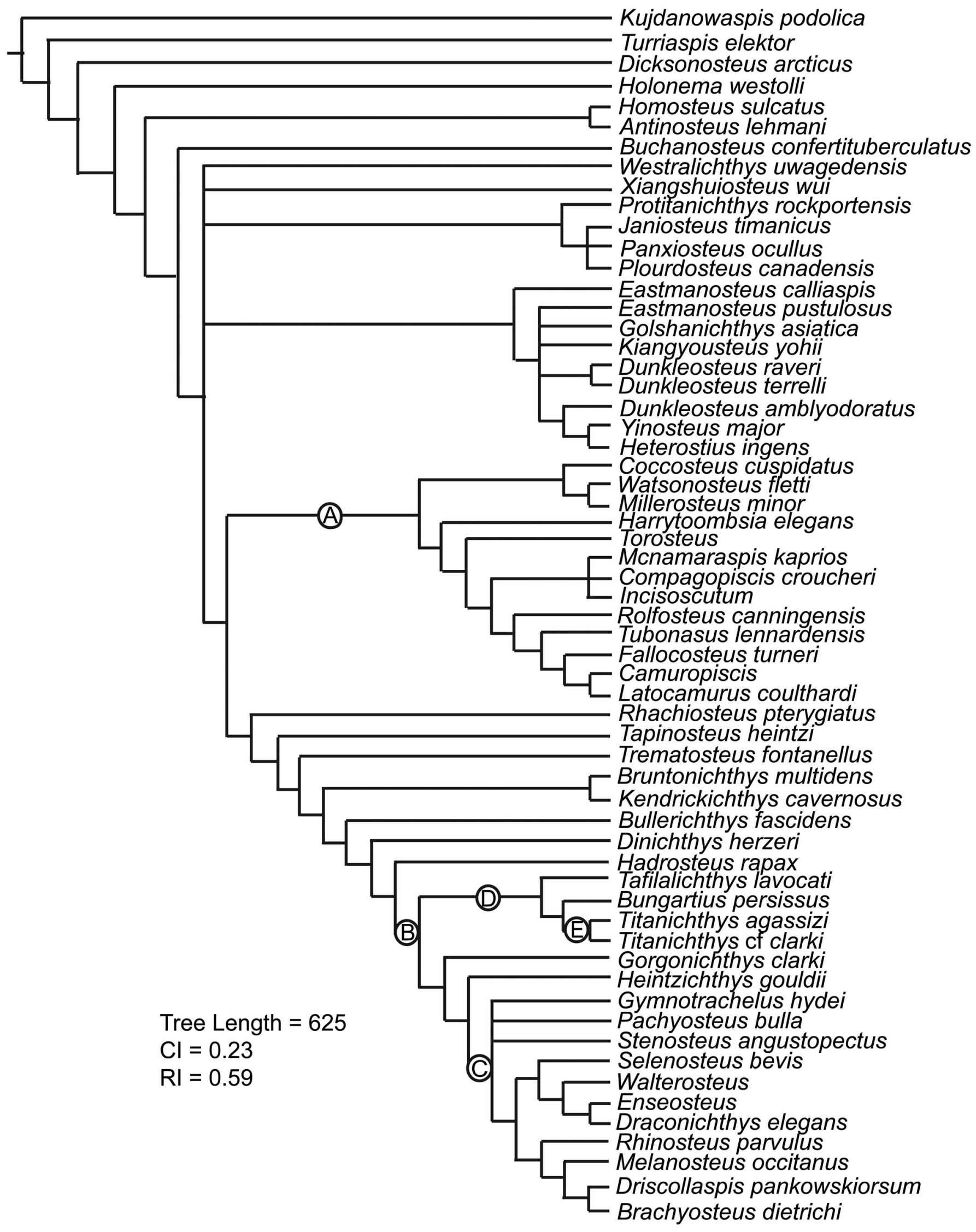

Figure 17. A strict consensus of 2769 trees from a parsimony analysis in PAUP. Major nodes are labeled: A = coccosteids, B = Aspinothoracida, $\mathrm{C}=$ Selenosteidae, $\mathrm{D}=$ mylostomatids? , and $\mathrm{E}=$ Titanichthyidae . 

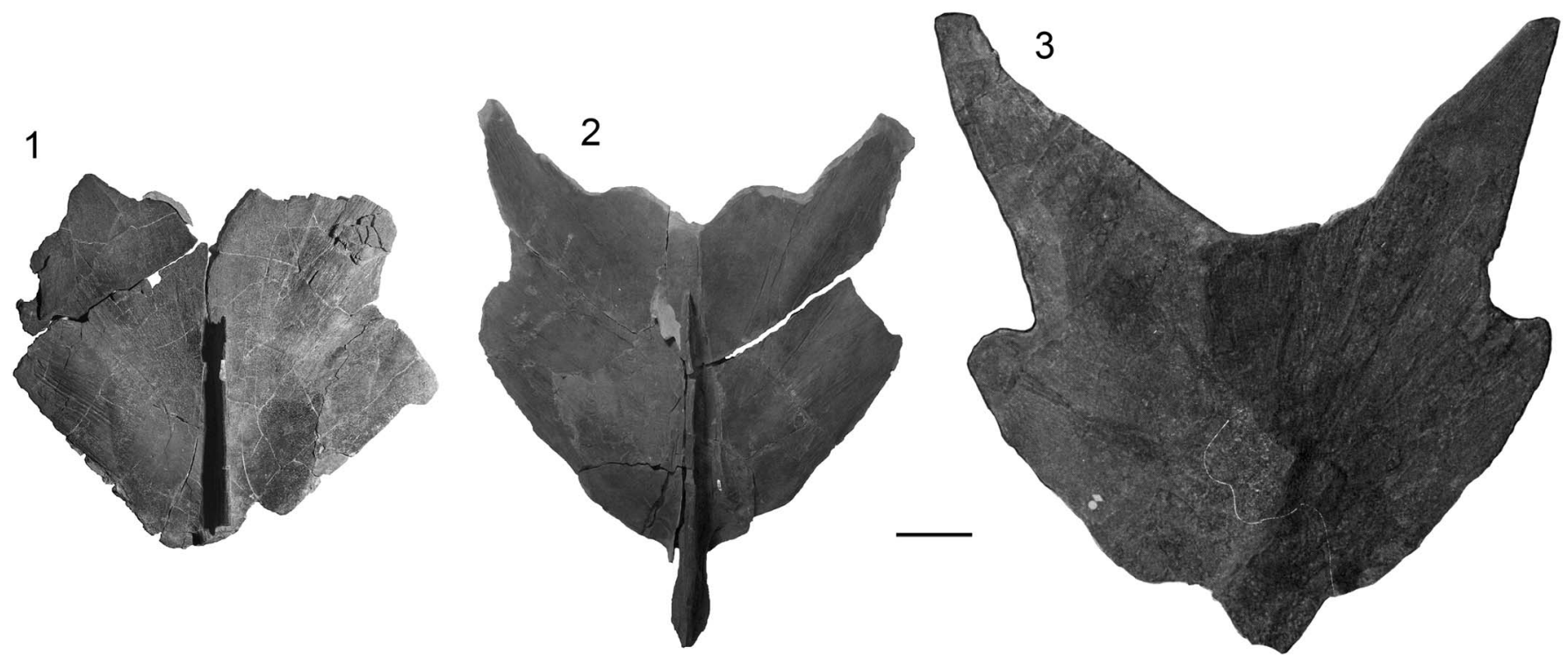

Figure 18. The median dorsal plates of Titanichthys arranged left to right in a putative growth series. (1) CMNH 50319 (Ti. cf. T. clarki, ventral view), (2) CMNH 8981 (Ti. cf. T. clarki, ventral view), and (3) AMNH 7315 (Ti. clarki, dorsal view). Scale bar $=10 \mathrm{~cm}$.

1942; Lehman, 1956; Denison, 1978). However, a lack of contact between the rostral and preorbital plates is known for other species (Rücklin, 2011; Rücklin et al., 2015) and, in general, placoderms have a weak suture between the rostral plate and the head shield (Goujet, 2001). Although the head shield of Titanichthys appears to be loosely articulated and thin compared to most arthrodires, parts of the thoracic shield-in particular the posterior dorsal lateral and median dorsal platehave become more integrated.

The posterior dorsal lateral plate of CMNH 50319 carries two insertions, one for the posterior lateral plate-an arrangement also found in Dunkleosteoidea (Carr and Hlavin, 2010) as well as Gy. hydei (Carr, 1994)-and a second for the posterolateral edge of the median dorsal plate, which is unique to the specimen. Posterior dorsal lateral plates have been recorded from $\mathrm{Ti}$. termieri specimens (Lehman, 1956), but they are incomplete posteriorly probably due their extreme thinness (only a few millimeters thick) in this region. However, the probable subadult status of CMNH 50319 could also mean that at least the upper portion of the insertion was modified and lost during growth by resorption. Due to the insertion of the median dorsal plate's lateral margin into the posterior dorsal lateral plate, the usually distinctive presence of two paired lateral processes of the median dorsal plate are obscured.

While the presence of an insertion for the median dorsal plate on the posterior dorsal lateral plate may be interpreted as ontogenetic, the reduced posterior superognathal of $\mathrm{CMNH}$ 50319 is probably apomorphic for Titanichthys. The relative lengths of the posterior superognathal to the inferognathal plate in advanced arthrodires (e.g., Euarthrodira) ranges from between approximately 30 to $50 \%$. However, the posterior superognathal of CMNH 50319 is only approximately $16 \%$ the length of the inferognathal, falling outside the range of other advanced arthrodires. The posterior superognathal also lacks any denticles or cusps that would articulate with the inferognathal. For this to be an ontogenetic feature would require dramatic growth late in life in the gnathal elements, which is unknown in other arthrodires (Snively et al., 2010).

While the inferognathal is the most characteristic element of Titanichthys, their orientation has been the subject of debate. The inferognathals were originally reconstructed so that the anterior ends project anteromedially, with the groove facing up, presumably to support the inferred tooth plates (Newberry, 1885). This orientation was disputed by Dunkle and Bungart (1942) who believed that the inferognathals had been placed upside down and interchanged from side to side; in their reconstruction the anterior portion of the inferognathal projects ventromedially. They based this orientation on the presence of a separate structure found in the groove of some Titanichthys specimens (CMNH 6163, CMNH 7366) that they identified as an anterior inferognathal, now known as the mentomandibular ossification of the Meckelian cartilage.

Lehman (1956) preferred the original inferognathal orientation of the groove facing dorsally, citing that the position of the inferognathal fragment on the left side of the head shield as being nearly in life position. However, the inferognathal must have been transported to have come to rest on the dorsal surface of the head shield and, thus, is not guaranteed to be near its original location. In contrast, the inferognathal of CMNH 50319 was found closely associated with the left suborbital, postsuborbital, and submarginal plates and, thus, had not been transported. The inferognathal of CMNH 50319 has the groove facing ventrally supporting the Dunkle and Bungart (1942) orientation. A consequence of interpreting the inferognathal of Titanichthys with the groove face ventrally is that the most anterior portion of the inferognathal projects ventrally below the rest of the inferognathal.

Within the pachyosteomorphs, only B. perissus (Dunkle, 1947) shares this ventrally projecting tip of the inferognathal. The presence of a ventral groove is considered plesiomorphic at 
the brachythoracid level (Lelièvre, 1995); however, it seems probable that in Titanichthys the groove was expanded to hold the meckelian cartilage as well as muscle attachments inferred from patterns on the internal surface of the groove that appear to represent muscle scars.

Subadult status of CMNH 50319.-We consider CMNH 50319 to represent a subadult specimen of Titanichthys based on the overall size of the preserved elements and the large diameter of the lateral fenestrae compared to the published figures of larger individuals (Newberry, 1885; Dean, 1909); we infer from this that the fenestrae diminished in size as the animal matured. Additionally, the inferognathal is significantly shorter than other Titanichthys specimens available for examination, possibly due to its age at time of death. The few studies that have discussed ontogeny in arthrodires have either focused on single elements, (i.e., inferognathals; Hlavin, 1976; Carr, 1991) or the entire headshield of taxa distantly related to Titanichthys (i.e. Gogcocoosteids; Trinajstic, 1995, 2009; Trinajstic and Hazelton, 2007). Despite ontogenetic uncertainty, most of the potential ontogenetic changes observed in these studies are unlikely to have impacted the characters states of CMNH 50319 used in the phylogenetic analysis. This is because the ontogenetic changes observed for D. terrelli (Hlavin, 1976) and coccosteids (Trinajstic, 1995; Trinajstic and Hazelton, 2007; Trinajstic and Dennis-Bryan, 2009) are either not treated as characters in this analysis, or the characters are categorical and not ambiguous in CMNH 50319.

In addition to the inferred diminishing size of the lateral fenestrae with age, the median dorsal plate of CMNH 50319 exhibits an unusual anterior border morphology that we believe is related to ontogeny. The median dorsal plate of both $\mathrm{CMNH}$ 50319 and CMNH 8981 exhibit a deep median embayment at the anterior border, in addition to the normal anterior embayment of aspinothoracids. In CMNH 50319, this embayment is more pronounced than that in CMNH 8981, which is the larger of the two specimens. AMNH 7315 (Dean, 1909) lacks this median embayment entirely, but has the largest overall anterior embayment and is also the largest specimen. This same pattern of loss of the median embayment with increased size is also seen in Dunkleosteus (Dean, 1909, fig. 61), although in that genus the median dorsal begins with an ovoid shape.

Taking size as a proxy for age, the three median dorsal plates, CMNH 50319, CMNH 8981, and AMNH 7315 can be interpreted as a putative growth series from smallest to largest (Fig. 18). During growth, either the lateral margin of the median embayment seen in CMNH 50319 is remodeled or the anterior margin of the median dorsal plate undergoes negative allometry with respect to the rest of the plate. In either case, the median embayment becomes less distinct with growth until it is indistinguishable from the anterior embayment of the nuchal. Of note, Eastman (1898, fig. 5) figures a median dorsal plate identified as belonging to a juvenile Ti. clarki, which lacks an anterior median embayment, but the assignment to Titanichthys is questionable. The development of the median embayment may potentially be used to give a relative age to Titanichthys specimens.

Titanichthys as a filter feeder.-The genus has traditionally been interpreted as a planktivore (Denison, 1978; Anderson,
2008) based on the absence of denticles, and the lack of shearing or crushing features on the inferognathals. Although this hypothesis remains untested, Titanichthys does show several characteristics that are convergent with giant suspensionfeeding organisms. These include: (1) a long and slender lower jaw relative to body length, (2) reduced orbit size, (3) lack of teeth, and, (4) large body size (e.g., whale shark; Friedman, 2011). It is possible that Titanichthys was the first massive vertebrate pelagic planktivore, with a lifestyle similar to that of the modern basking, whale, or megamouth sharks.

\section{Acknowledgments}

We would like to thank D. Zelinski for preparing CMNH 50319, the CMNH staff and volunteers for collecting and preparing the other materials described and examined for this project, T. Robison and the staff of the Cleveland Metro Parks for permission to collect CMNH 50319, D. Chapman and G. Jackson for sharing their knowledge of the Cleveland Shale fossils, L. Hall for his aid with figures, and R. Carr for helpful comments and discussions on placoderms. We would also like to thank H. Lelièvre, K. Trinajstic, and one anonymous reviewer for their comments and suggestions that helped to improve the quality of the manuscript. This work was a part of a senior thesis at Case Western Reserve University, which also provided a SOURCE travel grant to present this research at the combined Northeastern/North-central GSA meeting 2011.

\section{Accessibility of supplemental data}

Data available from the Dryad Digital Repository: https://doi. org/10.5061/dryad.5s500.

\section{References}

Anderson, P.S.L., 2008, Shape variation between arthrodire morphotypes indicates possible feeding niches: Journal of Vertebrate Paleontology, v. 28, p. $961-969$.

Asmuss, H., 1856, Das vollkommenste Hautskelet der bisher bekannten Thierreihe: an fossilen Fischen des alten rothen Sandsteins aufgefunden und aus ihren Resten erläutert, Dorpat: Gedruckt bei Schünmans Wittwe and C. Mattiesen, 39 p.

Bremer, B., Jansen, R.K., Oxelman, B., Backlund, M., Lantz, H., and Kim, K.-J., 1999, More characters of more taxa for a robust phylogeny - case study from the coffee family (Rubiaceae): Systematic Biology, v. 48, p. 413-435.

Carr, R.K., 1991, Reanalysis of Heintzichthys gouldii, an aspinothoracid arthrodire: Zoological Journal of the Linnean Society, v. 103, p. 349-390.

Carr, R.K., 1994, A redescription of Gymnotrachelus (Placodermi: Arthrodira) from the Cleveland Shale (Famennian) of northern Ohio, U.S.A.: Kirtlandia, v. 48, p. 3-21.

Carr, R.K., 1995, Opportunity knocked and no one was home: aspinothoracid arthrodires (Placodermi) from the Ohio Shale Formation (upper Devonian, North America): Geobios, v. 19, p. 81-83.

Carr, R.K., 1996, Stenosteus angustopectus sp. nov. from the Cleveland Shale (Famennian) of northern Ohio with a review of selenosteid (Placodermi) systematics: Kirtlandia, v. 49, p. 19-43.

Carr, R.K., and Hlavin, W.J., 2010, Two new species of Dunkleosteus Lehman, 1956, from the Ohio Shale Formation (U.S.A., Famennian) and the Kettle Point Formation (Canada, upper Devonian) and a cladistic analysis of the Eubrachythoraci (Placodermi, Arthrodira): Zoological Journal of the Linnean Society, v. 159, p. 195-222.

Carr, R.K., and Jackson, G.L., 2005, Diplognathus lafargei sp. nov. from the Antrim Shale (Upper Devonian) of the Michigan Basin, Michigan, USA: Revista Brasileira de Paleontologia, v. 8, p. 109-116.

Claypole, B.A., 1892, A new gigantic placoderm from Ohio: American Geologist, v. 10, p. 1-4. 
Claypole, B.A., 1893, The fossil fishes of Ohio, with a supplement by A. A. Wright: Ohio Division of Geological Survey Report, v. 7, p. 602-619.

Claypole, B.A., 1894, On a new placoderm Brontichthys clarki, from the Cleveland Shale: American Geologist, v. 14, p. 379-380.

Dean, B., 1901, On two new arthrodires from the Cleveland Shale of Ohio: New York Academy of Sciences Memoir, v. 2, p. 86-100.

Dean, B., 1909, Studies of fossil fishes (sharks, chimaeroids and arthrodires): Memoirs of the American Museum of Natural History, v. 9, p. 209-287.

Denison, R., 1975, Evolution and classification of placoderm fishes: Breviora, v. 432 , p. $1-24$

Denison, R., 1978, Handbook of Paleoichthyology: Placodermi, Volume 2: Stuttgart, New York, Gustav Fischer Verlag, 128 p.

Dennis, K., and Miles, R.S., 1979, A second eubrachythoracid arthrodire from Gogo, Western Australia: Zoological Journal of the Linnean Society, v. 67, p. 1-29.

Dennis, K., and Miles, R.S., 1980, New durophagous arthrodires from Gogo, Western Australia: Zoological Journal of the Linnean Society, v. 69, 43-85.

Dennis, K., and Miles, R.S., 1981, A pachyosteomorph arthrodire from Gogo, Western Australia: Zoological Journal of the Linnean Society, v. 73 , p. $213-258$

Dennis-Bryan, K., 1987, A new species of eastmanosteid arthrodire (Pisces: Placodermi) from Gogo, Western Australia: Zoological Journal of the Linnean Society, v. 90, p. 1-64.

Dunkle, D.H., 1947, A new genus and species of arthrodiran fish from the Upper Devonian Cleveland Shale: Scientific Publications of the Cleveland Museum of Natural History, v. 8, p. 103-117.

Dunkle, D.H., and Bungart, P.A., 1939, A new arthrodire from the Cleveland Shale Formation: Scientific Publication of the Cleveland Museum of Natural History, v. 8, p. 13-28.

Dunkle, D.H., and Bungart, P.A., 1940, On one of the least known of the Cleveland Shale Arthrodira: Scientific Publications of the Cleveland Museum of Natural History, v. 8, p. 29-47.

Dunkle, D.H., and Bungart, P.A., 1942, The infero-gnathal plates of Titanichthys: Scientific Publications of the Cleveland Museum of Natural History, v. 8, p. 49-59.

Dunkle, D.H., and Bungart, P.A., 1943, Comments on Diplognathus mirabilis Newberry: Scientific Publications of the Cleveland Museum of Natural History, v. 8, p. 73-84.

Dunkle, D.H., and Bungart, P.A., 1945, A new arthrodiran fish from the Upper Devonian Ohio shales: Scientific Publications of the Cleveland Museum of Natural History, v. 8, p. 85-95.

Dunkle, D.H., and Bungart, P.A., 1946, The antero-supragnathal of Gorgonichthys: American Museum Novitates, v. 1316, p. 1-10.

Eastman, C.R., 1898, Some new points in dinichthyid osteology: The American Naturalist, v. 32, p. 747-768.

Eastman, C.R., 1907, Devonic fishes of the New York formations: New York State Museum Memoir, v. 10, p. 1-235.

Ettensohn, F.R., 1987, Rates of relative plate motion during the Acadian Orogeny based on the spatial distribution of black shales: The Journal of Geology, v. 95 , p. $572-582$.

Friedman, M., 2011, Parallel evolutionary trajectories underlie the origin of giant suspension-feeding whales and bony fishes: Proceedings of the Royal Society of London. Series B Biological Sciences, v. 279, p. 944-951.

Gardiner, B.G., and Miles, R.S., 1990, A new genus of eubrachythoracid arthrodire from Gogo, Western Australia: Zoological Journal of the Linnean Society, v. 99 , p. $159-204$.

Goujet, D., 2001, Placoderm and basal gnathostome apomorphies, in Ahlberg, P.E., ed., Major events in early vertebrate evolution: paleontology, phylogeny, genetics and development: The Systematics Association, p. 209-222.

Gross, W., 1932, Die Arthrodira Wildungens: Geologische und Paläeontologische Abhandlungen, v. 19, p. 1-61.

Heintz, A., 1931, The anterior-lateral plate in Titanichthys: Journal of Natural History, v. 8, p. 208-212

Hlavin, W.J., 1976, Biostratigraphy of the Late Devonian black shales on the cratonal margin of the Appalachian geosyncline, Unpublished Ph.D. dissertation, Boston University, $388 \mathrm{p}$.

Hussakof, L., 1930, Dental elements in the arthrodire Titanichthys: Bulletin of the Geological Society of America, v. 41, p. 196

Kulczycki, J., 1957, Upper Devonian fishes from the Holy Cross Mountains (Poland): Acta Palaeontologica Polonica, v. 2, p. 285-395.

Lehman, J.-P., 1956, Les Arthrodires du Dévonien superieur du Tafilalet (sud Marocain): Notes et Mémoires du Service Géologique du Maroc, v. 129 , p. $1-114$.

Lehman, J.-P., 1977, Nouveaux arthrodires du Tafilalet et de ses environs: Annales de Paléontologie (Vertébrés), v. 63, p. 105-132.

Lelièvre, H., 1991, New information on the structure and the systematic position of Tafilalichthys lavocati (placoderm, arthrodire) from the Late Devonian of Tafilalt, Morocco, in Chang, M.-M., Liu, Y.-H., and Zhang, G.-R., eds., Early Vertebrates and Related Problems of Evolutionary Biology: Science Press, p. 121-130.
Lelièvre, H., 1995, Description of Maideria falipoui n. g., n. sp., a long snouted brachythoracid (Vertebrata, Placodermi, Arthrodira) from the Givetian of Maider (South Morocco), with a phylogenetic analysis of primitive brachythoracids: Bulletin du Muséum national d'Histoire naturalle, v. 17, p. 163-207.

Lelièvre, H., Feist, R., Goujet, D., and Blieck, A., 1987, Les vertebres Dévoniens de la Montagne Noire (sud de la France) et leur apport a la phylogénies des pachyostéomorphes (Placodermes Arthrodires): Palaeovertebrata, v. 17, p. $1-26$.

Long, J.A., 1987, A new dinichthyid fish (Placodermi: Arthrodira) from the Upper Devonian of Western Australia, with a discussion of dinichthyid interrelationships: Records of the Western Australian Museum, v. 13, p. 515-540.

Long, J.A., Mark-Kurik, E., and Young, G.C., 2014, Taxonomic revision of buchanosteid placoderms (Arthrodira) from the Early Devonian of southeastern Australia and Artic Russia: Australian Journal of Zoology, v. 62, p. 26-43.

M'Coy, F., 1848, On some new fossil fishes of the Carboniferous Period: The Annals and Magazine of Natural History, v. 2, p. 1-10.

Newberry, J.S., 1885, On the remains of giant fossil fish recently discovered in the Devonian rocks of North America: International Geologic Congress Scientific Communications, v. 3, p. 11-14

Newberry, J.S., 1887, Description of a new species of Titanichthys: Transactions of New York Academy of Sciences, v. 6, p. 164-165.

Newberry, J.S., 1889, Paleozoic Fishes of North America: US Geological Survey Monographs, v. 16, 340 p.

Pilgrim, B.L., and Franz-Odendaal, T.A., 2009, A comparative study of the ocular skeleton of fossil and modern chondrichthyans: Journal of Anatomy, v. 214 , p. $848-858$

Rücklin, M., 2011, First Selenosteid Placoderms from the Eastern Anti-Atlas of Morocco: osteology, phylogeny and paleogeographical implications: Palaeontology, v. 54 , p. 25-62.

Rücklin, M., Long, J.A., and Trinajstic, K., 2015, A new selenosteid arthrodire ('Placodermi') from the Late Devonian of Morocco: Journal of Vertebrate Paleontology, v. 35, p. e908896.

Snively, E., Anderson, P.S.L., and Ryan, M.J., 2010, Functional and ontogenetic implications of bite stress in arthrodire placoderms: Kirtlandia, v. 57, p. 53-60.

Stensiö, E.A., 1942, On the snout of arthrodires: Kungliga Svenska Vetenskapsakademiens Handlingar, v. 20, p. 1-32.

Stensiö, E.A., 1959, On the pectoral fin and shoulder girdle of the arthrodires: Kungliga Svenska Vetenskapsakademiens Handlingar, v. 8, p. 1-229.

Swofford, D.L., 2002, PAUP*. Phylogenetic Analysis Using Parsimony (*and Other Methods): Version 4b10. Sinauer Associates, Sunderland, Massachusetts.

Trinajstic, K., 1995, The role of heterochrony in the evolution of Eubrachythoracid Arthrodires with special reference to Compagopiscis croucheri and Incisoscutum ritchei from the Late Devonian Gogo formation, Western Australia: Geobios, v. 19, p. 125-128.

Trinajstic, K., 2009, Polymorphism, variation, and evolutionary change in early vertebrates from the Gogo Formation, Western Australia: Journal of the Royal Society of Western Australia, v. 92, p. 399-405.

Trinajstic, K., and Dennis-Bryan, K., 2009, Phenotypic plasticity, polymorphism and phylogeny within placoderms: Acta Zoologica, v. 90, p. 83-102.

Trinajstic, K., and Hazelton, M., 2007, Ontogeny, phenotypic variation and phylogenetic implication of arthrodires from the Gogo Formation, Western Australia: Journal of Vertebrate Paleontology, v. 27, p. 571-583.

Trinajstic, K., Sanchez, S., Dupret, V., Tafforeau, P., Long, J., Young, G. Senden, T., Boisvert, C., Power, N., and Ahlberg, P.E., 2013, Fossil musculature of the most primitive jawed vertebrates: Science, v. 341, p. $160-164$

Woodward, A.W., 1891, Catalogue of the fossil fishes in the British Museum (Natural History).

Young, G.C., Leliévre, H., and Goujet, D., 2001, Primitive jaw structure in an articulated Brachythoraci arthrodire (placoderm fish: early Devonian) from Southern Australia: Journal of Vertebrate Paleontology, v. 21, p. 670-678.

Zagger, G.W., 1995, Conodont Biostratigraphy and Sedimentology of the Latest Devonian of Northeast Ohio: Unpublished M.S. Thesis, Case Western Reserve University, $224 \mathrm{p}$.

Zhu, Y.-A., and Zhu, M., 2013, A redescription of Kiangyousteus yohii (Arthrodira: Eubrachythoraci) from the Middle Devonian of China, with remarks on the systematics of the Eubrachythoraci: Zoological Journal of the Linnean Society, v. 169, p. 798-819.

Zhu, Y.-A., Zhu, M., and Wang, J,-Q., 2015, Redescription of Yinosteus major (Arthrodira: Heterostiidae) from the Lower Devonian of China, and the interrelationships of Brachythoraci: Zoological Journal of the Linnean Society, v. 176, p. 806-834.

Accepted 22 August 2016 